\title{
Analysis of an Experimental Cortical Network: ii) Connections of Visual Areas 17 and 18 After Neonatal Injections of Ibotenic Acid
}

\author{
G.M. Innocenti and P. Berbel ${ }^{\mathrm{a}}$ \\ Institute of Anatomy, University of Lausanne, Rue du Bugnon, \\ 1005 Lausanne, Switzerland
}

aPresent address:

Department of Histology and Institute of Neuroscience

Faculty of Medicine

University of Alicante

03690 Alicante, Spain.

\section{SUMMARY}

Lesions of cortical areas 17 and 18 were produced in newborn kittens by local injections of the excitotoxin ibotenic acid. In the adult this results in a microcortex which consists of superficial layers I, II and III, in the absence of granular and infragranular layers. Horseradish peroxidase, alone or wheat germ agglutinin conjugated, was injected in the microcortex or in the contralateral, intact areas 17 and 18. The microcortex maintains several connections characteristic of normal areas 17 and 18 of the cat. It receives afferents from the dLGN, and several visual areas of the ipsilateral and contralateral hemisphere. However, it has lost its projections to dLGN, superior colliculus, and, at least in part, those to contralateral visual areas. Thus

Reprint address:

G.M. Innocenti,

Institute of Anatomy,

University of Lausanne,

Rue du Bugnon 9,

Lausanne 1005, Switzerland. some parts of the microcortex receive from, but do not project into, the corpus callosum. In addition, the microcortex maintains afferents from ipsilateral and contralateral auditory areas AI and AII which are normally eliminated in development.

Key words: cortex development, cortex connections, excitotoxins, microgyria, ibotenic acid.

\section{INTRODUCTION}

As described in detail elsewhere /29/, injections of ibotenic acid (ibo) in the visual cortex (areas 17 and 18) of kittens on their second or third postnatal day, result, near the center of the injection, in the formation of a microcortex consisting exclusively of the supragranular layers I, II and III. At the transition between the microcortex and the intact cortex, the granular and infragranular layers progressively reappear in a characteristic outside-in sequence. The formation of a microcortex seems to be due to a differential sensitivity of postmigratory and migrating neurons to the neurotoxin; while the first are killed the second are spared and complete migration, giving rise to the cortical layers they are normally destined to.

Thus, the neonatal ibo injection results in the formation of a "simplified" neocortex, which may facilitate the analysis of cell-cell and cell- 
substrate interactions in development as well as that of the relations between neocortical structure and function. In addition, from the point of view of its architectonics and pathogenesis, the microcortex obtained by neonatal injections of ibo resembles microgyria, a congenital malformation of the human cortex, often associated with mental retardation, epilepsy and possibly dyslexia (for ref. and discussion see /29/); it may, therefore, provide a model for the study of this malformation.

Here we describe some general aspects of the afferent and efferent connectivity of the microcortex, and in particular three cortico-cortical projections to areas 17 and 18, i.e., the callosal projections from contralateral areas 17-18 and AI-AII, and the ipsilateral projections from areas AI-AII, all of which are known to undergo massive axonal elimination in development $/ 10,11,25,31-33,35,36 /$. The development of the latter projection to the microcortex was also studied and will be compared to the normal development of the same projection $/ 33 /$. As discussed earlier $/ 28,30-32 /$, the fact that most cortico-cortical transient axons either do not enter the cortex or, when they do, do not elaborate terminal arbors suggests that axons which grow to the cortex recognize some aspect of the target and this determines their fate. The selective deletion of cortical layers produced by neonatal injections of ibo may help to clarify if cortical layers are specifically involved in the selection that corticopetal afferents undergo in development. Preliminary reports of these results were published /30,34/.

\section{MATERIALS AND METHODS}

Experiments were performed on 23 kittens, born in our breeding colony. About one half of the kittens were obtained from timed pregnancies and were delivered on day $65 \pm 2$ post-conception. All kittens received injections of ibo in areas 17 and 18 of the right hemisphere between postnatal days (pd) 1 and 14, and were subsequently injected with tracers, usually WGAHRP, in their visual or auditory areas at different ages. Table 1 shows ages at ibo injection and at death, doses of ibo and of tracers. Methods for ibo injections were described in Innocenti and Berbel $/ 29 /$, those for tracer injection and tissue processing in Innocenti et al. /30/. During surgery and injections the animals were anesthetized with Ketalar (25-35 mg/kg, i.m., depending on age) supplemented by a mixture of $\mathrm{N}_{2} \mathrm{O}, \mathrm{O}_{2}$ and isoflurane (Forene) as needed. Local anesthesia (2\% Xylocaine) was applied to the wounds. Perfusions were performed under deep barbiturate anesthesia (> $40 \mathrm{mg} / \mathrm{kg}$, i.p.). The distribution of labeled neurons was drawn from selected sections using a computer-linked microscope $120 \%$ Reconstructions of the distribution of neurons were performed using a computer and an appropriate software. The locations of the ibo lesions and of the injection sites were defined with reference to standard stereotaxic planes /59/ and standard electrophysiological maps of the visual areas /60/ and of the dLGN /61/. As described in detail elsewhere $/ 29 /$, in all the animals the lesions consist of a core where the deep part of layer III and all the layers underneath are destroyed, layers II and the top of layer III are spared and form a characteristic microcortex. At the periphery of the injection, progressively deeper portions of the cortex are spared; typically though, layer V and sometimes a part of IV, are destroyed further away from the injection center than layer VI.

The animals were divided in 2 experimental groups (Table 1). Afferents to the microcortex were studied in four animals (IBO 2, 7, 9 and 69) which received HRP or WGA-HRP injections into the right areas 17 and 18, where ibo had been injected at birth.

In IBO 2, the HRP injection was caudal to the ibo lesion and overlapped minimally with it (see below). No detailed description of this experiment will be given since the distribution of neurons labeled by the HRP injections was similar to that found in normal animals $/ 30$.

In IBO 7, the neonatal injections of neurotoxin damaged the cortex of the lateral, postlateral and suprasylvian gyri approximately between the stereotaxic planes P8 and A5. The core of the lesion was between P7 and A4.5. At its greatest mediolateral extension (P3, P4) it occupied the whole lateral-postlateral gyrus from the bottom of the splenial sulcus to that of the lateral sulcus, but it also involved the bottom of the suprasylvian sulcus. Caudally, the lesion became restricted to the convexity of the postlateral gyrus and rostrally to the medial and lateral banks of the lateral gyrus. Partial destruction of layers IV- 
VI and clearing of layer $\mathrm{V}$ were found over the rest of areas 17 and 18 and also involved 19, 21a, PMLS, PLS, VLS and 21b. Judging from the distribution of extracellular precipitate, the WGA-HRP injection was centered roughly at P3; it occupied approximately $2 \mathrm{~mm}$ rostrocaudally and the same dorsoventrally on the dorsal convexity of the postlateral gyrus, involving areas 17 and 18, entirely within the region of severe ibo lesion (Fig. 3).

In IBO 9, a more circumscribed lesion was found. The cortex of the lateral and postlateral gyri was damaged between P9 and P1. The core of the lesion was between P8.5 and P1.5 and at its greatest mediolateral extension (P5-6) it occupied the whole extent of area 18, the dorsal half of area 17, and it involved over a few hundred microns the bottom of the suprasylvian sulcus (area 21a). As in IBO 9, from caudal to rostral the lesion came to occupy parts of 17 and 18 away from the dorsal convexity of the gyrus. Partial destruction of layer VI and clearing of layers IV-V extend over a broader territory including a restricted part of area 19. WGAHRP injections were placed along the postlateral gyrus and span between P8 and P4, on the dorsal convexity of the gyrus, as in IBO 7, and were similarly confined to within the region of severe ibo lesion.

In IBO 69 , the cortex was damaged between $\mathrm{P} 8$ and $\mathrm{A} 3$. The core of the lesion was restricted to areas 17 and 18 and covered a V-shaped territory whose apex was on the convexity of the postlateral gyrus at approximately $\mathrm{P} 4$ and stretched rostrally, separately over 17 and 18, approximately as far as A4. Partial destruction of
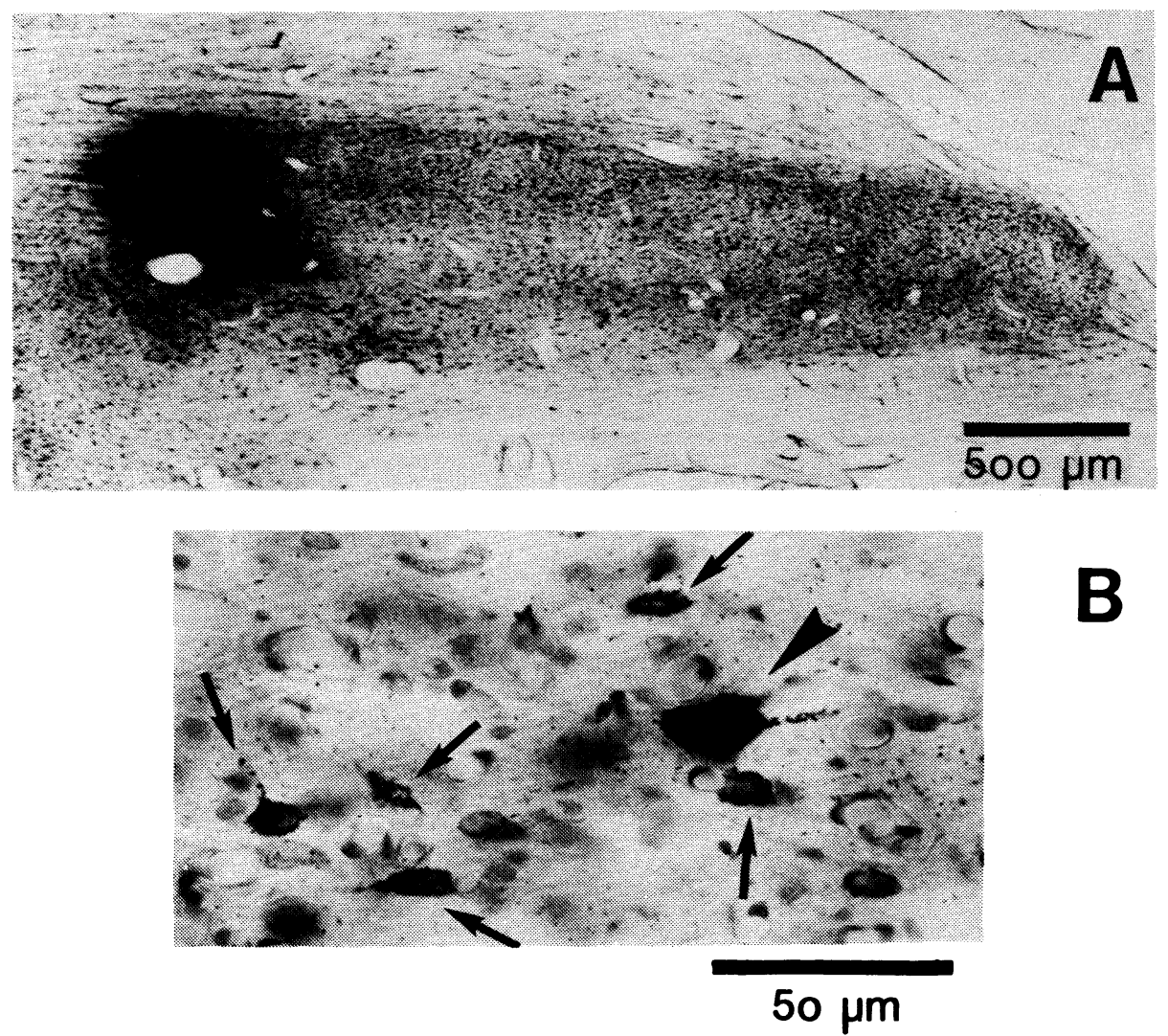

Fig. 1: A, photomicrograph of the dLGN in IBO 9 showing dense retrograde labeling in the medialmost part of the nucleus (on the left) after a WGA-HRP injection in the microcortex. B, photomicrograph of individual labeled neurons in the dLGN of IBO 7 (toluidine blue counterstaining) after a WGA-HRP injection in the microcortex. Arrows point to individual labeled neurons of medium size, arrowhead to a large labeled neuron. Soma size and the distribution of dendritic stems of the large and medium neurons resemble those of Guillery's 121/ class 1 and 2 thalamic relay cells (c.f. Fig. $1 / 24 /$ ). 

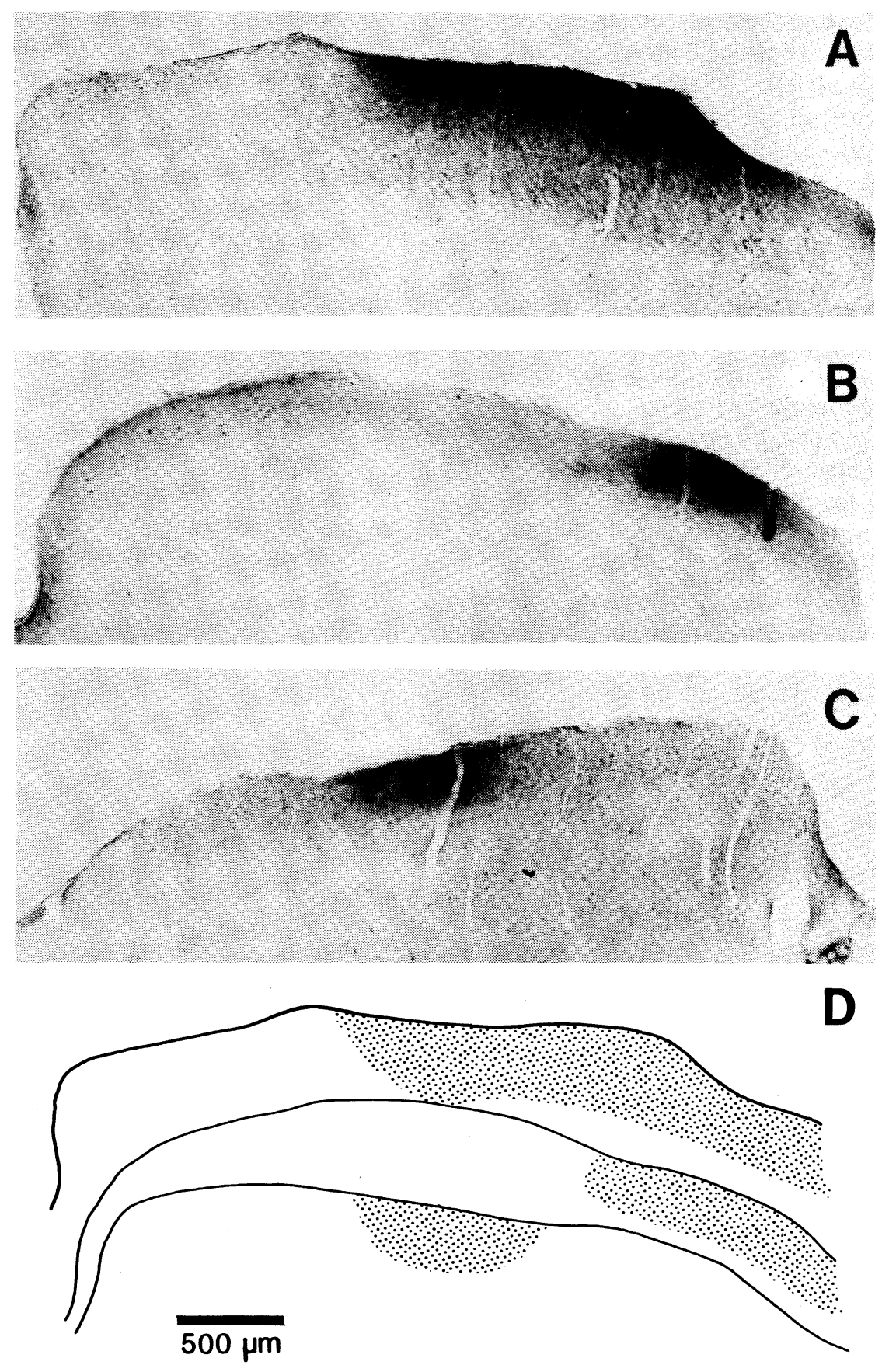

Fig. 2: Photomicrographs of WGA-HRP labeled cortico-collicular projections at corresponding rostrocaudal collicular levels in three animals. A, terminal field labeled in a normal animal (IBO 81c) after a large injection involving areas 17 and 18 to the exclusion of their caudalmost portion. Medial is to the left. $B$, terminal field labeled in an animal (IBO 69) where parts of areas 17 and 18 corresponding to the center of the visual field were microcortical. The labeling is restricted to a narrow lateral portion of the colliculus. $\mathrm{C}$, terminal field labeled by an injection in the intact areas 17 and 18 (IBO 12) and restricted to the center of the visual field (medial is to the right). D, schematic representation of the terminal fields in A-C, showing their respective topographic positions; D, was drawn mirror-reversed. Notice that in B no anterograde labeling is found in the part of the colliculus corresponding to microcortex. 
TABLE 1. Summary of experiments

\begin{tabular}{|c|c|c|c|c|c|c|c|}
\hline \multirow{2}{*}{$\begin{array}{l}\text { Animal } \\
\text { code }\end{array}$} & \multicolumn{2}{|c|}{ Age (days) at } & \multicolumn{2}{|c|}{$\begin{array}{c}\text { Dose of } \\
\text { IBO }\end{array}$} & \multicolumn{3}{|c|}{ Tracer injections } \\
\hline & $\begin{array}{c}\mathrm{IBO} \\
\text { injection }\end{array}$ & death & $\underset{\omega l \mathrm{l} x}{\mathrm{IBC}}$ & $\left.\frac{\mu \mathrm{g}}{\mu \mathrm{l}}\right)$ & site & type & $\mathbf{x} \mu l$ \\
\hline IBO 2 & $2 \frac{1}{2}$ & $361 / 2$ & 2.5 & $\times 30$ & $17 / 18 \mathrm{R}$ & $50 \%$ HRP & $4 \times 0.55$ \\
\hline IBO 6 & 1 & 35 & 2 & $\times 30$ & $17 / 18 \mathrm{~L}$ & $50 \%$ HRP & $4 \times 0.5$ \\
\hline IBO 7 & 2 & 81 & 2 & $\times 30$ & $17 / 18 \mathrm{R}$ & $10 \%$ WGA-HRP & $1 \times 0.15$ \\
\hline IBO 8 & 2 & 92 & 2 & $\times 30$ & $17 / 18 \mathrm{~L}$ & FB, DY, RL & $1 \times(0.1,0.15,0.2)$ \\
\hline IBO 9 & 2 & 100 & 2 & $\times 30$ & $17 / 18 \mathrm{R}$ & $10 \%$ WGA-HRP & $3 \times 0.15$ \\
\hline IBO 12 & 1 & 97 & 2.5 & x 30 & $17 / 18 \mathrm{~L}$ & $10 \%$ WGA-HRP & $4 \times 0.2$ \\
\hline IBO 17 & 2 & 3 & 2.5 & $\times 30$ & $17 / 18 \mathrm{~L}$ & $10 \%$ WGA-HRP & $\begin{array}{l}1 \times 0.2 \\
1 \times 0.5\end{array}$ \\
\hline IBO 19 & 2 & 8 & 2.5 & $\times 30$ & $17 / 18 \mathrm{~L}$ & $10 \%$ WGA-HRP & $\begin{array}{l}1 \times 0.4 \\
1 \times 0.7\end{array}$ \\
\hline IBO 62 & 3 & 366 & $* 1$ & $\times 30$ & 17/18 R & $10 \%$ WGA-HRP & $2 \times 0.15$ \\
\hline IBO 69 & 2 & 374 & 1 & $\times 30$ & $17 / 18 \mathrm{R}$ & $10 \%$ WGA-HRP & $1 \times 0.5$ \\
\hline IBO 11 & 1 & 90 & 2.5 & $\times 30$ & AI/AII $R$ & $10 \%$ WGA-HRP & $5 \times 0.15$ \\
\hline IBO 13 & 1 & 104 & 2.5 & $\times 30$ & AI/AII $R$ & $10 \%$ WGA-HRP & $8 \times 0.15$ \\
\hline IBO 26 & 2 & 55 & 2.8 & x 10 & AI/AII R & $10 \%$ WGA-HRP & $1 \times 0.22$ \\
\hline IBO 27 & 2 & 208 & 2 & $\mathbf{x} 10$ & AI/AII R & $10 \%$ WGA-HRP & $5 \times 0.24$ \\
\hline IBO 29 & 2 & 155 & 1 & $\times 20$ & AI/AII R & $10 \%$ WGA-HRP & $6 \times 0.15$ \\
\hline IBO 30 & 2 & 196 & $* 0.5$ & $\times 30$ & AI/AII $R$ & $10 \%$ WGA-HRP & $5 \times 0.24$ \\
\hline IBO 43a & 3 & 41 & 1 & $\mathrm{x} 30$ & AI/AII R & $10 \%$ WGA-HRP & $\begin{array}{l}1 \times 0.15 \\
1 \times 0.23\end{array}$ \\
\hline IBO 45 & 3 & 18 & 1 & x 30 & AI/AII R & $10 \%$ WGA-HRP & $1 \times 0.1$ \\
\hline IBO 46 & 3 & 27 & 1 & $\times 30$ & $\begin{array}{l}\text { AI/AII R } \\
\text { AI/AII L }\end{array}$ & $\begin{array}{l}10 \% \text { WGA-HRP } \\
10 \% \text { WGA-HRP }\end{array}$ & $\begin{array}{l}5 \times 0.1-0.3 \\
2 \times 0.1-0.7\end{array}$ \\
\hline IBO 47 & 3 & 11 & 1 & $\times 30$ & AI/AII $R$ & $10 \%$ WGA-HRP & $1 \times 0.03$ \\
\hline IBO 49 & 7 & 167 & 1 & $\times 30$ & AI/AII R & $10 \%$ WGA-HRP & $5 \times 0.22$ \\
\hline IBO 96 & 6 & 65 & 1 & $\times 30$ & AI/AII R & $10 \%$ WGA-HRP & $4 \times 0.15-0.22$ \\
\hline IBO 98 & 2 & 14 & 1 & $\times 30$ & AII R & $10 \%$ WGA-HRP & $1 \times 0.045$ \\
\hline
\end{tabular}

Survival after WGA-HRP injection was $24 \mathrm{~h}$, after HRP injection, $48 \mathrm{~h}$. Asterisks denote doses which did not provoke a lesion. Aqueous solutions of FB and DY were 1.5 and 2\%, respectively. AI, first auditory area; AII, second auditory area; DY, diamidino yellow; FB, fast blue; HRP, horseradish peroxidase; L, left hemisphere; R, right hemisphere; RL, rhodamine latex microspheres; WGA, wheat germ agglutinin; 17, area 17; 18, area 18.

layer VI and clearing of layers IV-V extended over a broader portion of areas 17 and 18 and in the region of their maximal mediolateral extent may have included a small part of area 19. The WGA-HRP injection site was much larger than in IBO 7 and 9; it comprised the injured cortex and the underlying white matter and, especially at the most rostral levels extended into normal cortex, both rostrally and laterally, involving the gray matter of area 19 and lightly that of the medial bank of the suprasylvian sulcus (area PMLS) 154/. With this large injection site we intended to visualize, unlike in the other two animals, not only the afferents to the microcortex but also those to the surrounding intact cortex.
Two control animals received tracer injections in areas 17 and 18. One of these animals (IBO 81c; not included in Table 1; also described in ref. $/ 33 /$ ) was a normal adult of unknown age. It received 6 injections $(0.5 \mu \mathrm{l}$ each) of $10 \%$ WGA-HRP, which filled the lateral and postlateral gyri of the right hemisphere between the stereotaxic planes P8 and A10 where they involved nearly completely areas 17 and 18 and part of area 19. The dLGN contained labeled neurons everywhere within its rostral two thirds. This injection site is similar in its location to that of IBO 69 but is slightly larger.

The second animal (IBO 62; Table 1) received an ibo injection on pd 3 , which, for 
unknown reasons, failed to provoke the lesion. The WGA-HRP injection filled the lateral and postlateral gyri of the right hemisphere between P8.5 and P4 involving both areas 17 and 18. Retrograde labeling was found in the dLGN between A5 and A6.5, i.e., roughly at intermediate rostrocaudal levels, and was confined to the medial half of the nucleus.

Projections into the corpus callosum from the ibo injected cortex were studied in a second group of animals (IBO 6, 8 and 12) where tracers were injected in the hemisphere contralateral to the ibo injection. The most interesting of these animals was IBO 12 in which the lateral and postlateral gyri were injured between the stereotaxic planes P4 and A6. The core of the lesion was between P4.5 and A4 and involved large portions of areas 17 and 18, and possibly, the medialmost portion of area 19. There was complete loss of neurons and therefore discontinuity of the cortex over a few hundred microns near the crown of the postlateral gyrus, corresponding to the center of the ibo injection. The WGA-HRP injection filled the crown of the lateral and postlateral gyri in the left, intact hemisphere, between P9 and P4, extending ventrally for about $2 \mathrm{~mm}$ over areas 17, 18 and the underlying white matter. Labeled neurons were found in the retinotopically corresponding part of dLGN.

In IBO 6, the lesion was similar in its location and extent to that of IBO 12 but less severe, since no complete destruction of the visual cortex was found. The HRP injection was larger than in IBO 12 and involved the lateral and postlateral gyri, apparently in their whole mediolateral extent, between the stereotaxic planes P5 and A8, which resulted in complete labeling of the rostralmost three fourths of the dLGN. In IBO 8, the lesion extended between P10 and A8. Its core was between $\mathrm{P} 9$ and $\mathrm{A} 5$; at its greatest mediolateral extent, it involved the whole of areas 17, 18 and most of area 19 and the suprasylvian areas near the fundus of the suprasylvian sulcus were also involved over several hundred microns. Three fluorescent tracers, from caudal to rostral: rhodamine latex beads (RL) /40/, diamidino yellow (DY) /41/ and fast blue (FB) /3/ were placed between P7 and A4. These injection sites were confined to within regions of the lateral gyrus homotopic to those containing the core of the lesion. The DY injection was proba- bly too small to be effective and indeed did not label neurons either ipsilaterally in the dLGN or contralaterally.

Callosal connections of the microcortex were also studied in two animals (IBO 17 and 19: Table 1) which received WGA-HRP contralateral to the neonatal ibo injection, respectively simultaneously to it and 5 days later. In IBO 17, loss of cortical neurons with the exception of those in a thin superficial layer near the bottom of layer I, and of the migrating neurons, was found, as is typical $24 \mathrm{~h}$ after the injection (see ref. /29/) over a broad region comprising the cortex of the lateral and postlateral gyri in their full mediolateral extent between the caudal end of the hemisphere and the rostral end of the dLGN. The WGA-HRP in the contralateral hemisphere span an approximately similar territory. There was a similar lesion and WGA-HRP injection in IBO 19 in which unfortunately the site of ibo injection, as sometimes occurs $/ 29$, was undergoing cystic degeneration.

Projections from auditory areas to the microcortical areas 17 and 18 were traced anterogradely with WGA-HRP in a second group of animals (Table 1). The strategy in 6 of these experiments (IBO 11, 13, 26, 27, 29, 30) was to vary systematically the amounts and concentration of ibo at injection in order to try to define the smallest lesion capable of inducing stabilization of the auditory-to-visual projection (see Results). Consequently, the damaged cortex (including microcortex and the transitional cortex) extended from P8 to A6 in IBO 13, which was the animal with the largest lesion, and from P6 to A3.5 in IBO 26, which had the smallest lesion with the exception of IBO 30, where no lesion was found. In all cases the lesion was centered on areas 17 and 18 with minimal or no involvement of area 19 near the bottom of the lateral sulcus and no involvement of suprasylvian cortex. In 5 other experiments (IBO 43a, 45, 46, 47, 98) the amount of ibo was kept constant but the age of WGA-HRP injection was varied between pd 10 and 40 , i.e., within the period in which auditoryto-visual projections normally disappear $133 /$. Severity and location of the ibo lesions resembled those described above although given the smaller size of the brains direct quantitative comparison was not possible. Finally, in two animals (IBO 49 and 96) ibo was injected on pd 6 and 7 , at which ages even more extreme reduc- 
tions of cortical thickness can be obtained /29\%. In all these kittens WGA-HRP was injected in the ectosylvian auditory areas ipsilateral to ibo injections aimed at $\mathrm{AI}$ and $\mathrm{AII}$.

\section{RESULTS}

\section{Subcortical connections}

In ibo injected kittens, the dLGN ipsilateral to the microcortex had usually maintained its normal shape and cellular composition although it was often smaller than on the intact side. In a few cases, those in which the ibo injection resulted in regions of complete cortical destruction $129 /$, degenerated sectors retinotopically corresponding to the destroyed cortex could be found.

In animals (IBO 7, 9, 69), where the tracer was injected in the microcortex, labeled neurons were found in the thalamic nuclei dLGN and lateralis posterior. In the dLGN, they extended over all laminae and had either large (20-30 $\mu \mathrm{m}$ in diameter) or medium size $(10-20 \mu \mathrm{m}$ in diameter) somata. Size and shape of these neurons resembled those of Guillery's /21/ class 1 and 2 neurons, suggesting that both classes still projected to the visual areas (Fig. 1). The position of the labeled neurons in the dLGN indicated maintenance of at least roughly normal topological relations between dLGN and cortex. Indeed, in the two animals (IBO 7 and 9) the HRP injection was restricted to the crown of the postlateral gyrus, in a region of central visual field representation $/ 60 /$ the labeling was found in the retinotopically corresponding, medialmost $1 / 5$ th of the dLGN, centered around the stereotaxic plane A5 and extending rostrocaudally for about $1 \mathrm{~mm}$ (Fig. $1 \mathrm{~A}$ ). In contrast, in IBO 69, the HRP injection extended over most of the posterolateral and lateral gyri; retrograde labeling was found nearly throughout the whole dLGN. Since labeled neurons were not counted, nor was the topography of the projection studied in detail (such studies are under way), these findings do not exclude the possibility of subtle changes in the geniculocortical projection.

In all these animals, most significantly in those where the injection site seemed restricted to the injured part of areas 17 and 18 (IBO 7 and 9) labeled neurons were also found in the claustrum.

The anterograde transport obtained with WGA-HRP injections in the microcortex in the experiments described above was also studied. Since the neonatal ibo-injections destroy the infragranular layers $/ 29 /$ which are the source of projections to the superior colliculus (SC) $/ 17 /$, thalamus /17/ and claustrum /46/, no projections to these structures were expected. Indeed, no projection to SC was found in IBO 7 and 9 while in IBO 69 , consistent with the location of the lesion, with that of the tracer injection in areas 17 and 18, and with the retinotopicity of the cortico-collicular projection, labeling was restricted to portions of the colliculus representing visual field locations at about $10^{\circ}$ $20^{\circ}$ below the horizontal meridian /4/ (Fig. 2).

A light extracellular precipitate was found in parts of the dLGN retinotopically corresponding to the microcortex and in the claustrum in IBO 9 and 69 but not in IBO 7. The precipitate was interspersed among labeled neurons. It is probably due to filling of fine dendritic branches or of initial axon collaterals.

\section{Intrahemispheric corticocortical afferents}

The analysis of intrahemispheric projections was performed in (IBO 7 and 9) with tracer injections restricted to the microcortex. In both animals, retrograde labeling was found in visual areas 17, 18, 19, 20a, 21a, 21b, VLS, PMLS, PLLS and AMLS (Fig. 3) as in normal animals (see ref. $/ 60 /$ ) or in animals whose intact hemisphere was injected (IBO 6, 8 and 12). In all these areas, as in normal animals, the projections originated more heavily or exclusively from the infragranular layers, especially layer VI (Fig. 3). No quantitative analysis of the topographical distribution of the labeled neurons was performed, but in general, although the injection sites were restricted and indeed labeled the dLGN only at positions roughly corresponding to the region of area centralis (see above), the labeling extended broadly over the visual field representations in the various areas. This was particularly striking in area 17 itself where a continuous band of labeling extended all the way to the medial periphery of this area in the 
Pd $2-99-100$

IBO 9

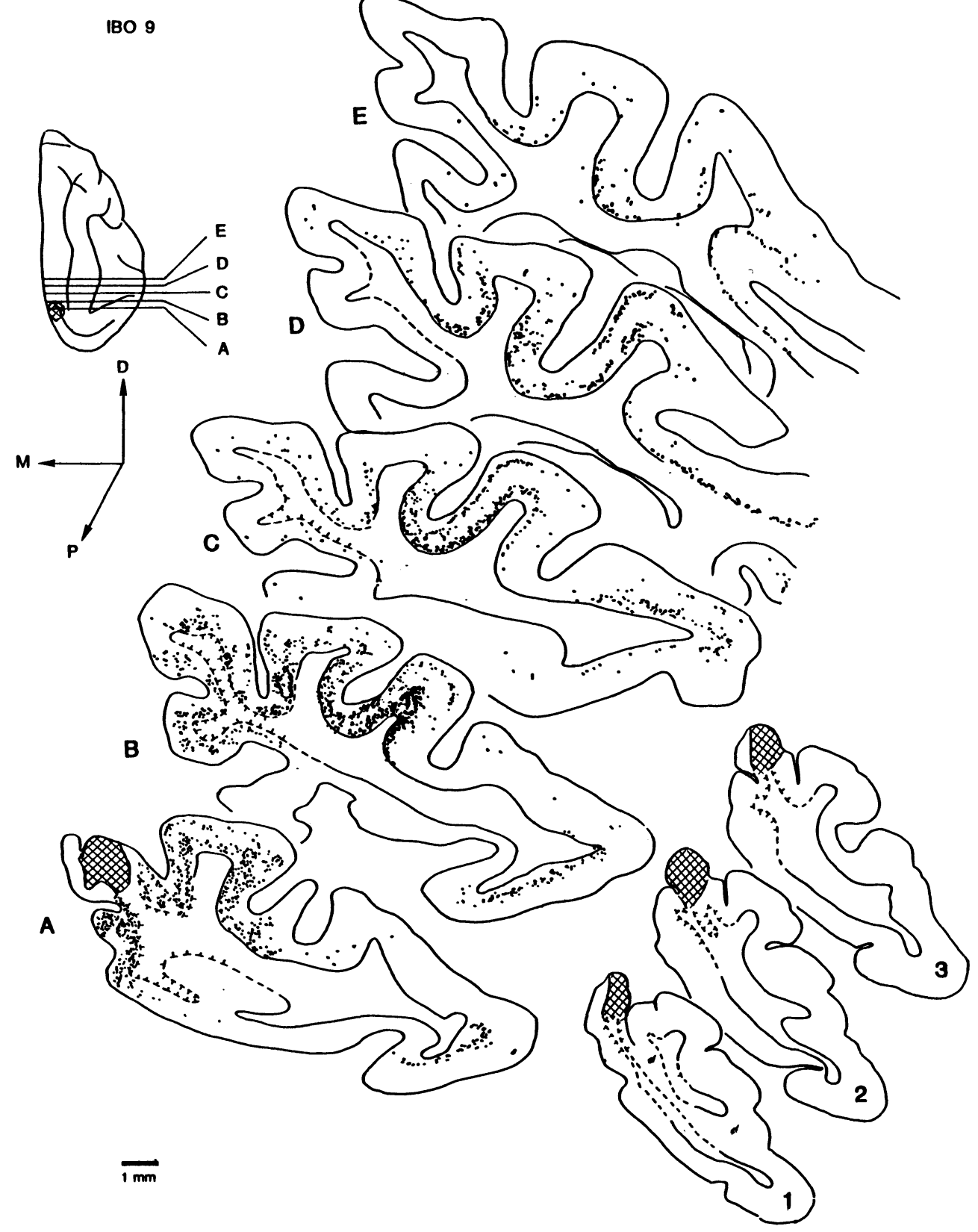

No. 3: Retrograde labeling of intrahemispheric cortico-cortical afferents to microcortical areas 17 and 18 . Age of the animal at ibo injection, WGA-HRP injection, and death, and animal code are indicated. The injection site (hatched) is shown in A, in small section drawings (1-3 from posterior to anterior) and on brain figurine. The levels of sections (A-E) are indicated on brain figure. In each section a continuous line denotes the bottom of normal layer $\mathrm{VI}$, an interrupted line denotes the bottom of the thinned layer VI, usually accompanied by degeneration of layer V. T(s) denote the bottom of the three layered microcortex (see ref. 29, for cytoarchitectonic descriptions). Arrows indicate dorsal (D), medial $(M)$ and posterior (P) directions. Notice that areas 17 and 18 receive afferents from large portions of the occipital cortex including several visual areas; those from areas 17 and 18 originate from neurons close to the bottom of microcortex and in $A$ and $B$ the whole mediolateral extent of area 17 projects to the injection site. Only a narrow portion of the dLGN was labeled by the same injection (Fig. 1A). 
splenial sulcus and beyond, i.e., 5 - $6 \mathrm{~mm}$ away from the periphery of the injections (Figs. 3, 4). A similarly uninterrupted band of labeled neurons extended through area 18 into area 19. This is very different from what we previously found in normal adult animals (see Figs. 4, 8 and 9 in ref. $/ 35 /$ ) or, in the present study, in animals whose intact hemisphere was injected. In all these normal cases, injections on the crown of the lateral or postlateral gyrus labeled neurons in restricted portions of areas 17 and 18 extending over about $2 \mathrm{~mm}$ from the periphery of the tracer injection, although a few neurons could be found further away. We found no convincing evidence of clustered distribution of the projection neurons (Figs. 3, 4) which is a well known characteristic of the intrinsic connectivity of areas 17 and 18 in the adult $/ 18,19,49 /$ (see also Fig. 9 in ref. $/ 35 /$ ) as well as of the connectivity between areas 17 and $18 / 55 /$ (see also Figs. 8 and 12 in ref. /35/). Nevertheless, our injections may have been too large to reveal clustered connections and no quantitative techniques for the detection of periodic distributions of labeled neurons /6/ were applied; hence this negative finding is worth further investigations. The broad distribution of labeled neurons in areas 17 and 18 obtained after tracer injections restricted to the top of the lateral and postlateral gyri resembled that found after similar injections in newborn kittens /10/.

In the microcortex, labeled neurons extended from the white matter to the bottom of layer I. Since a large fraction of the intrinsic projections in 17 and 18 and of the 17 to 18 projection originate from supragranular layers (examples in ref. $/ 35 /$ ), the finding is consistent with the notion 129/ that the microcortex consists of supragranular layers III and II.

In addition to those from the expected visual areas, non-negligible projections were also found from area 7 , most clearly at its most rostral level explored, and from areas AI-AII. The latter projection will be described in detail below. Some neurons were also labeled in areas $20 \mathrm{~b}$, $21 \mathrm{~b}, \mathrm{DLS}$, and in the splenial region, including the splenial visual area of Kalia and Whitteridge $138 /$ as well as the splenial cingulate cortex.

\section{Interhemispheric cortico-cortical connections}

The analysis of the distribution of callosal neurons afferent to the microcortex was performed in IBO 7, 9 and 69. After tracer injections restricted to the microcortex (IBO 7, 9 ) or including part of the surrounding normal cortex (IBO 69) labeled neurons were densest in contralateral areas 17, 18, 19, 21a, PMLS and PLLS. In contrast, no labeled neurons were found in 20a and $20 \mathrm{~b}$ and very sparse ones in $21 \mathrm{~b}$ and VLS (Figs. 5, 6). Thus these ventral visual areas did not appear to contribute significant callosal projections to the microcortex although they did send significant ipsilateral projections to it. The distribution of labeled neurons resembled that previously reported for normal cortex $124,42,63-65 /$. In particular, an asymmetry between callosal and ipsilateral connections of the ventral visual areas with areas 17 and 18 similar to that observed here can be deduced from previously published works (cp. refs. /64,65/ with ref. /67/). The radial distribution of labeled callosal neurons also resembled that found in normal animals $/ 24 /$, i.e., homotopic projections from 17 and 18 originated mainly from supragranular layers although a few neurons were found in infragranular layers, mostly layer VI; in contrast, the relative contribution of the infragranular layers became progressively greater in areas 19 and 21a and was overwhelming in PMLS and PLLS (Figs. 5, 6) /42/.

As in normal adult cats $/ 24 /$, the origin of callosal projections in areas 17 and 18 was restricted to near their common border. We had the impression that in these areas there may have been fewer labeled neurons than in normal cats but did not attempt to quantify this difference. In any case, the distribution differed from the widespread one found in the same areas in the newborn kitten. Thus, unlike what seems to be the case for other connections, more clearly for the auditory-to-visual intra- and interhemispheric projections (see below), the juvenile exuberant callosal projections from medial 17 to the microcortex were not stabilized. Nor were these projections to the surrounding 


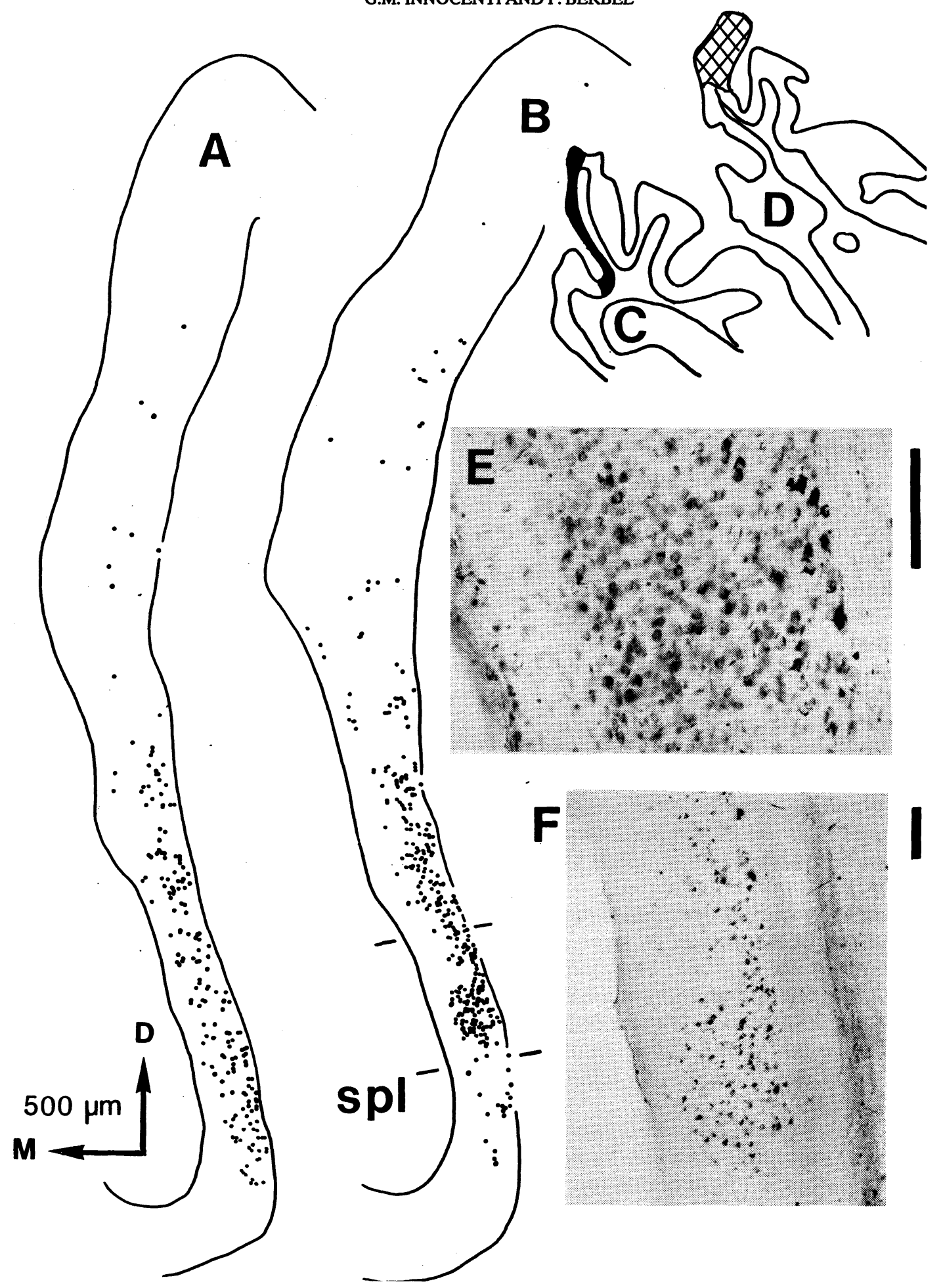

Fig. 4: Retrograde labeling in the medial part of area 17, following an injection in the dorsal parts of microcortical areas 17 and 18 (IBO 7). A is $240 \mu \mathrm{m}$ rostral to B which corresponds to the black portion of C. The part of B denoted by vertical bars is shown enlarged in F. D shows the center of the injection site (cross hatched) and is $1440 \mu \mathrm{m}$ rostral to $C$. E shows the distribution of labeled neurons at a location similar to that of $F$ but in an adjacent toluidine-blue stained section. Calibration bars in $E$ and $F$ are $100 \mu \mathrm{m}$. Notice that labeled neurons are at the bottom of the cortex, particularly numerous near the splenial sulcus (spl), i.e., several $\mathrm{mm}$ from the periphery of the injection, in a region of three-layered microcortex. 
Pd 2- $99-100$

IBO 9

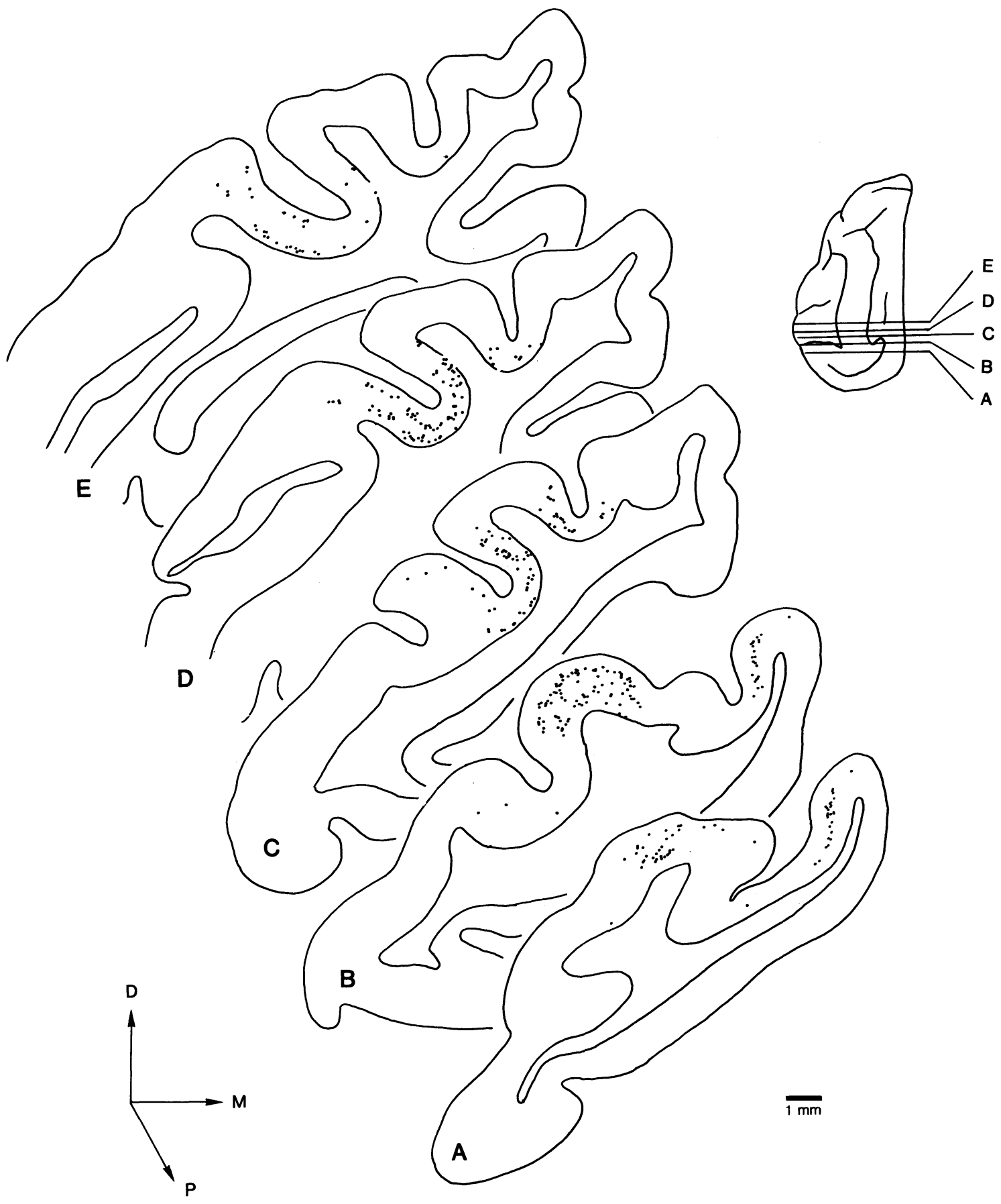

Fig. 5: Retrograde labeling of interhemispheric afferents to microcortical areas 17 and 18 in the same animal shown in Fig. 3. The levels of sections (A-E) are indicated on the brain figurine. Other conventions as in Fig. 3. Notice that the microcortex receives afferents from several contralateral dorsal visual areas but, unlike for intrahemispheric projections, not from ventral visual areas. 
Pd $2-372-374$

IBO 69

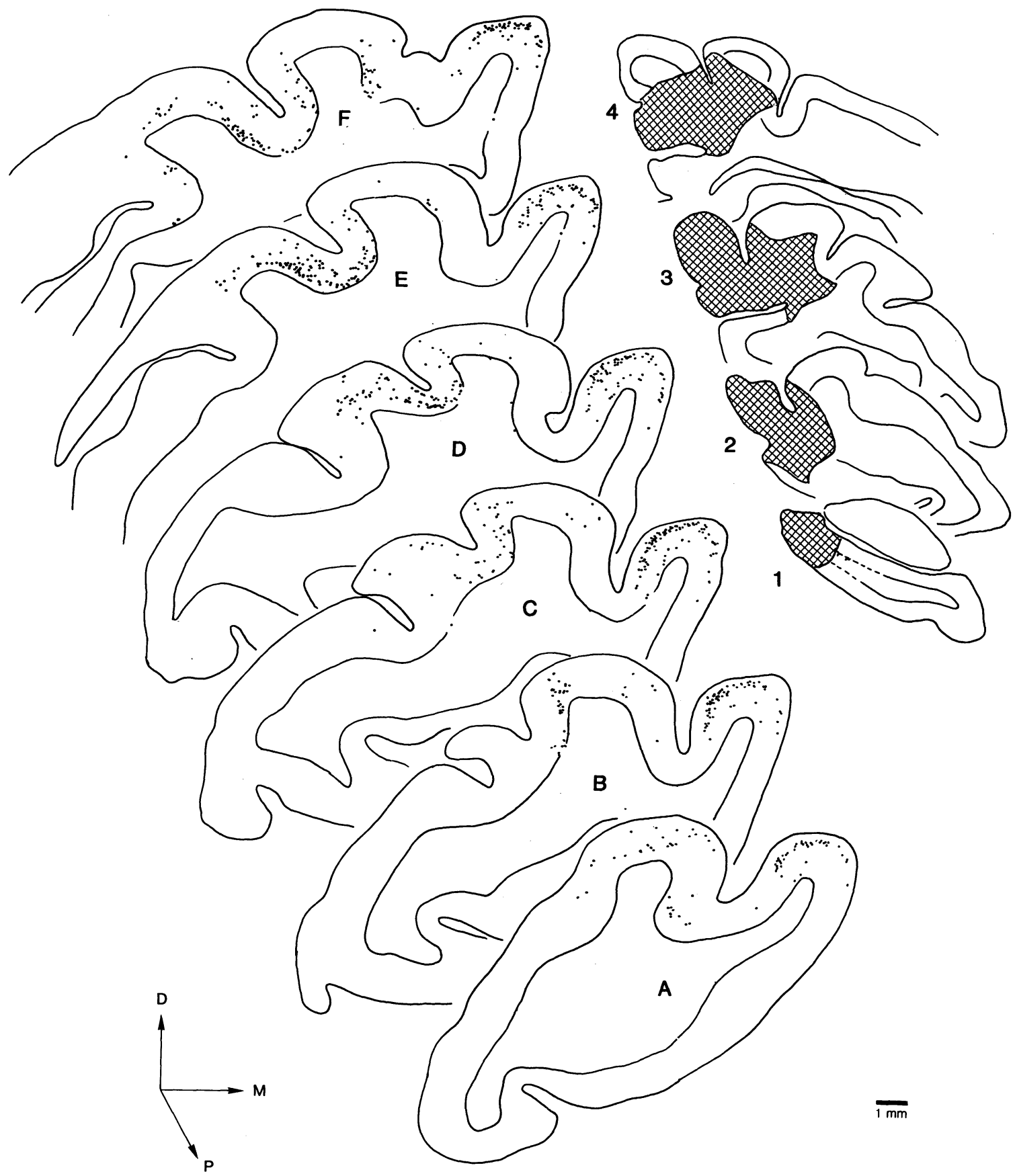

Fig. 6: Retrograde labeling of interhemispheric afferents to microcortical areas 17 and 18 and the surrounding normal cortex. The injection site (hatched) is shown in the reduced section drawing; the microcortex, whose extent and location are described in "Methods", is nearly completely involved but intact parts of 17,18 and 19 are involved as well. The distribution of labeling is similar to that found in a normal brain (c.f. Fig. 4 in ref. 24). Levels of sections are similar to those in Fig. 5. Other conventions as in Figs. 3-5. 

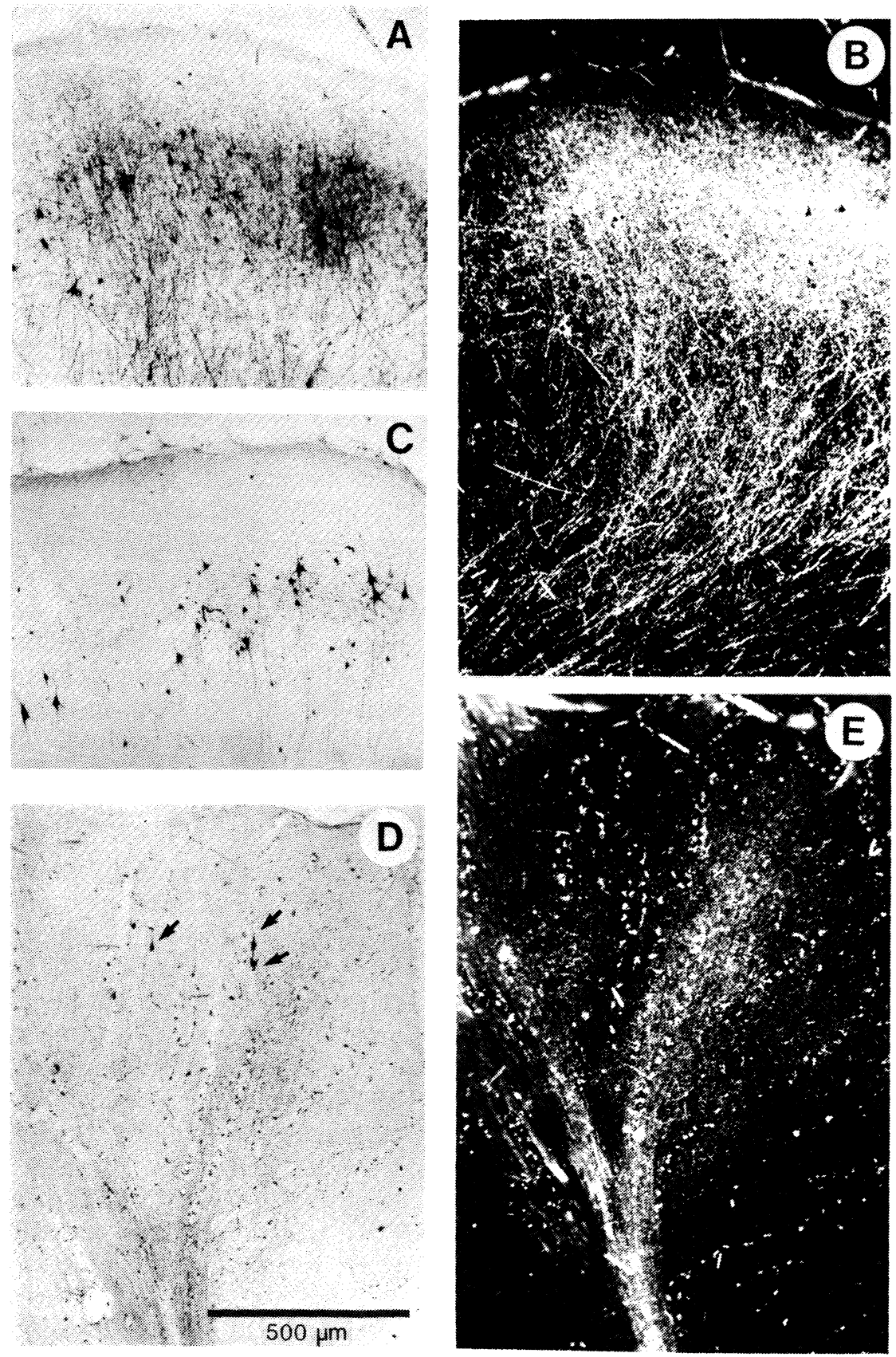

Fig. 7: A, Photomicrograph of anterogradely labeled callosal axons and retrogradely labeled callosal neurons (including their axon and some of its collaterals) near the $17 / 18$ border, in a part of cortex reciprocally connected with the normal areas 17 and 18 (IBO 69). B, Polarized-light photomicrograph of the same region and of deeper portions of the cortex and white matter. C. Photomicrograph of retrogradely labeled callosal neurons (including their axon and some of its collaterals) near the $17 / 18$ border, in a part of cortex which projects to microcortical areas 17 and 18 (IBO 69). D. Photomicrograph of anterogradely labeled callosal axons in the microcortex, presumably near the 17/18 (IBO 6) border. E, Polarized-light photomicrograph of the same region. Notice that the microcortex receives axons from its contralateral homologue (labeled neurons in $C$ and axons in D, C), but does not project to it, hence the absence of anterogradely labeled axons in C, while in D, E only 3 labeled neurons (arrows) can be seen. 
normal cortex stabilized as shown by the animal IBO 69 (Fig. 6) where the latter was also involved by the injection. Labeled neurons were restricted to portions of areas 17 and 18 homotopic to the injection, indicating that the microcortex maintained point-to-point relations with its intact homologue.

No anterograde transport to areas 17 and 18 of the contralateral hemisphere was found in IBO 7 and 9 (Fig. $7 \mathrm{C}$ ), indicating that the callosal projections of the microcortex are nonreciprocal as retrograde transport experiments from these areas confirmed (see below). IBO 69, where the tracer injection extended to the normal cortex, also had no anterograde transport to regions homotopic to the microcortex while this was present in regions homotopic to the normal cortex. This confirms that the rostrocaudal point-to-point topography of callosal projections was, at least grossly, preserved in ibo-injected animals.

Projections into the corpus callosum from the ibo injected cortex were studied in IBO 6, 8 and 12 (Table 1) in which, respectively, HRP, WGAHRP and fluorescent tracer injections were placed in the lateral and postlateral gyri contralateral to the microcortex.

The callosal connections of primary visual areas in IBO 12 had several interesting features. Confirming the anterograde results mentioned above, no callosal neurons, but anterograde labeling was found in parts of areas 17 and 18 corresponding to the microcortex (Fig. $7 \mathrm{D}, \mathrm{E}$ ). The anterograde labeling was restricted to a 500 - $1000 \mu \mathrm{m}$ wide region near the crown of the postlateral gyrus, which in normal adults would correspond to the border between areas 17 and 18. All microcortical layers were labeled. Labeled callosal neurons were found in parts of the lateral and postlateral gyri which had been spared by the ibo injections. At the transition between normal cortex and microcortex these neurons acquired a progressively deeper location, closer to the white matter, before disappearing (Fig. 8). The change in their radial position appeared determined by the concomitant progressive loss of the infragranular and granular layers $/ 29 \%$.

As in normal adult cats $/ 24 /$ the callosal neurons were restricted to a $2-4 \mathrm{~mm}$ wide region near the crown of the postlateral gyrus, which in normal adults would correspond to parts of areas 17 and 18 near their common border. However, the density of labeled neurons in portions of area 17 between the crown of the postlateral gyrus and the suprasplenial sulcus was higher than what we previously observed in normal cats, especially at the more rostral levels where, approaching the center of the ibo lesion, callosal neurons had disappeared from their normal location in area 18 and the adjacent portion of area 17; it was also higher than in animals in the present study, whose microcortex had been injected with tracers (cp. sections A-C in Fig. 6 and A-F in Fig. 8).

In IBO 6 , the callosal connections of the microcortex were similar to those found in IBO 12 in two respects. First, no labeled callosal neurons were found near the center of the ibo lesion but they progressively reappeared away from it. Second, terminating callosal axons were found in the absence of callosal neurons in the ibo injured cortex at a location similar to where they would have been in normal animals. As in IBO 12, labeled callosal neurons extended considerably further into 17 than in normal adults. However, the tracer was injected on pd 35 which is before callosal neurons have acquired fully adult distribution.

IBO 8 confirmed the absence of callosal projections from the microcortex and the existence of a rostrocaudal topography in the remaining projection but not the expansion into area 17 of the callosally projecting zone.

Preliminary information on the development of the callosal connections in ibo-injected animals were obtained in IBO 17 and 19 which were sacrificed, respectively, $24 \mathrm{~h}$ and 6 days after the ibo injection, $24 \mathrm{~h}$ after large WGAHRP injections in the contralateral hemisphere which filled the whole lateral and postlateral gyri contralateral to the ibo lesion. As described elsewhere $/ 29 /, 24 \mathrm{~h}$ after an ibo injection only a thin layer of intact neurons is found near the bottom of layer I. No labeled neurons were found in this part of the cortex, but they reappeared at the periphery of the lesion. Anterogradely labeled callosal axons, as in normal animals $/ 32 /$ massively entered the cortex as far as the top of layer I, only near the crown of the lateral gyrus, presumably near their normal target, the border between areas 17 and 18. In the rest of the gyrus, callosal axons terminated closer to the surface of the brain than in normal 
Pd $1-96-97$

IBO 12

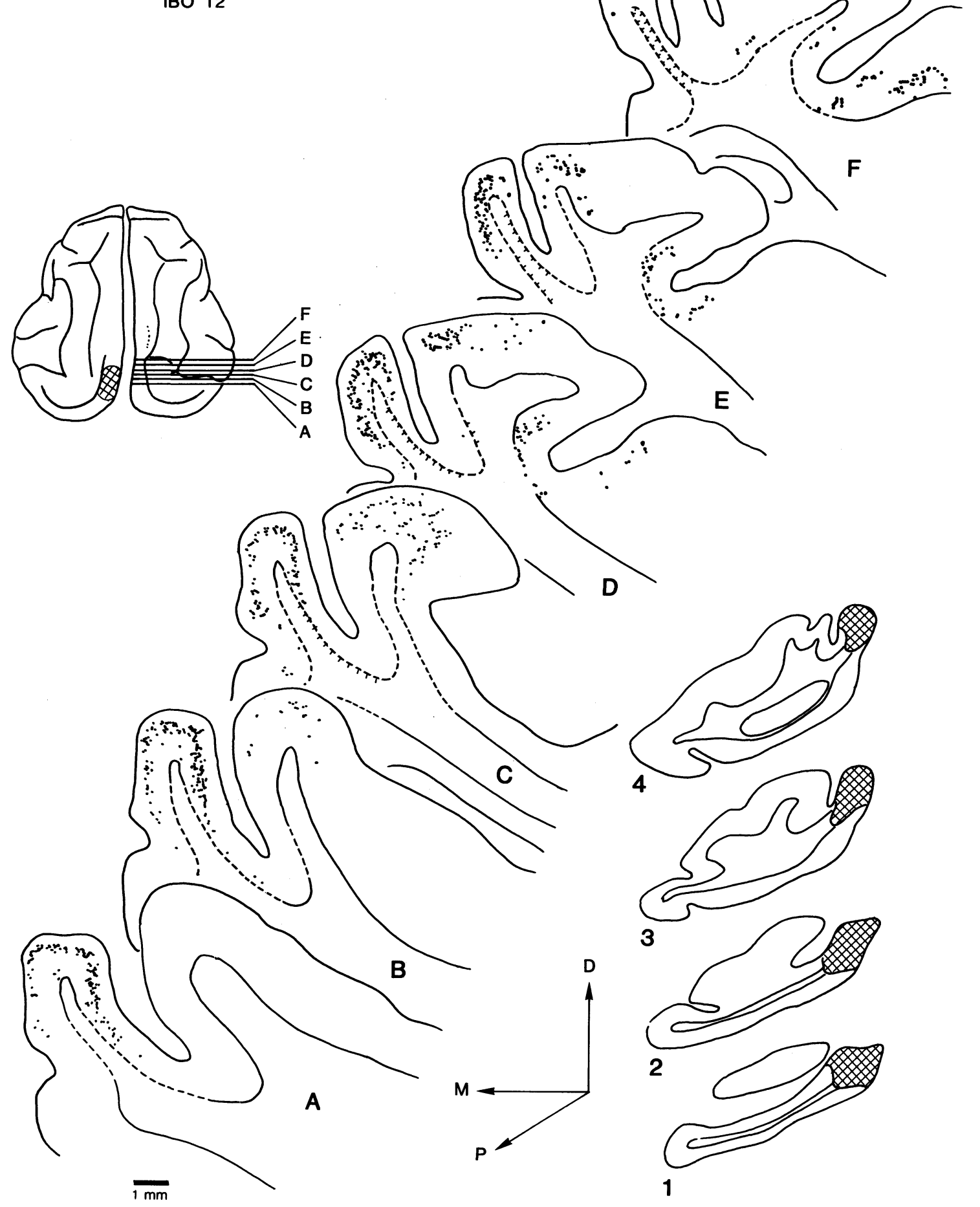

Fig. 8: Retrograde labeling of interhemispheric efferents from microcortical areas 17 and 18 (and other dorsal visual areas). All conventions are as in Figs. 3-6. Notice that labeled neurons disappear in the three layered microcortex; they extend further medially into 17 than in normal brains (c.f. Figs. 5 and 6). 
animals, i.e., they extended through parts of the cortex which consisted only of degenerating debris but exceptionally through the layer of intact neurons.

The situation was unchanged 6 days after the ibo lesion, i.e., the front of transitory callosal axons remained confined to the white matter, thus presumably below the neurons which had completed migration in the time between ibo injection and sacrifice (see ref. /29/). In this animal, however, only projections to the cortex at the transition between the normal and the injected cortex could be evaluated since the latter was undergoing cystic degeneration, as it happens in some cases $/ 29 /$.

These findings are consistent with those in older animals, in particular concerning the selective distribution of terminating callosal axons seen in the adult microcortex. In addition, they suggest that the presence of healthy neurons may prevent the growth of callosal axons in regions which will not receive callosal afferents in the adult.

\section{Afferents from auditory areas}

In IBO 7, 9 and 69 labeled neurons were found bilaterally on the lateral convexity of middle ectosylvian gyrus, and in the banks of the superior end of the posterior ectosylvian sulcus. This region corresponds to the low frequency representation in AI and possibly AII /58/. The labeling was restricted to a patch similar in extent and location in the three animals, surrounded by unlabeled regions and therefore separated from the labeled portion of the suprasylvian visual areas PLLS and ALLS of Palmer et al. /54/ (Fig. 9).

In the ipsilateral hemisphere, the patch spanned rostrocaudally 2700 (IBO 9), 3360 (IBO 7 ) and 3480 (IBO 69) $\mu \mathrm{m}$ and approximately the same distance mediolaterally. Judging by the morphology of the nearby dLGN the labeling extended between the stereotaxic planes A4.5 - 5 and A8.5 - 9. Usually $30-34$ labeled neurons per section were found which gave estimates (uncorrected for double counts) of 1080 (IBO 9), 1290 (IBO 7), 1580 (IBO 69) neurons over the whole region in each animal.

In the contralateral hemisphere, the patch spanned about $2200 \mu \mathrm{m}$ in both IBO 9 and 69 , and could not be appreciated in its total rostrocaudal extent in IBO 7. The contralateral patch extended less far forward than the ipsilateral one, spanning between the stereotaxic planes A4.5 and $6.5-8$. This is consistent with the finding that in normal development a sharper rostrocaudal point-to-point topographical correspondence exists for contralateral than for ipsilateral auditory-to-visual projections $/ 10,32 /$. Usually, 8 16 labeled neurons per section were found which gave estimates (uncorrected for double counts) of 200 (IBO 9) and 420 .(IBO 69) neurons over the whole region in each animal.

Ipsi- and contralaterally projecting neurons were usually lightly labeled. They were mostly small and occasionally medium size pyramids in layers II and III, rarely in layer VI. This radial distribution of the neurons strikingly differed from that of neurons projecting to areas 17 and 18 from the lateral suprasylvian cortex, most of which are in layer VI and a few in supragranular layers $/ 65,68 /$. The possibility that stellate cells contribute to the projection from auditory cortex cannot be excluded, given the incompleteness of the labeling and the fact that in each animal several sections did not cut the cortex perpendicularly to the pial surface. In some sections, most frequently in IBO 69 , the labeled neurons were segregated in $300-600 \mu \mathrm{m}$ wide clusters separated by empty spaces.

As described in detail elsewhere $/ 30 /$, only a few neurons, most of which in layer VI were found in auditory areas following injections in areas 17 and 18 in normal animals or in the normal hemisphere of ibo injected animals. Very few labeled neurons were also found in IBO 2 , where the HRP injection was in the injured hemisphere but caudal to the lesion and invaded the latter minimally if at all.

No anterograde transport to the auditory areas was found from either microcortex or normal cortex. This is consistent with the fact that no visual-to-auditory projections appear to exist postnatally $/ 33 /$.

In order to study the pattern of termination of the auditory projection in the visual areas, $\mathrm{AI}$ and AII were injected with WGA-HRP in 12 kittens of different ages, whose areas 17 and 18 had been injected with ibo on pd 1, 2, 3, 6 or 7 (Table 1). The 8 oldest kittens were used to study the adult projection from auditory cortex to the 
visual microcortex, the others, to study its development (see below).

In these animals, precision in the location of the injection site was critical since, as described above, the area containing the neurons of origin of the auditory to visual projection is only about $4 \mathrm{~mm}^{2}$. On the other hand, the deep layers (mainly layer VI) of the lateral suprasylvian areas project to areas 17 and 18 even in normal animals (see Fig. 9 in ref. /33/). In order to be sure that these neurons were not involved, injections were usually laterally placed on the convexity of the ectosylvian gyrus and may not have involved all the neurons projecting to the microcortex. The absence of labeling in i) thalamic nuclei other than those which are known to project to the auditory areas, ii) in the visual areas (see ref. /33/), and iii) the contralateral suprasylvian areas were taken as evidence that no uptake of tracer had occurred in the lateral suprasylvian areas. The distribution of retrograde labeling at homotopic contralateral sites provided an additional control that uptake of tracer had indeed occurred in the part of AIAII where neurons projecting to 17 and 18 were expected to be.

\section{Pd 2-79-81}

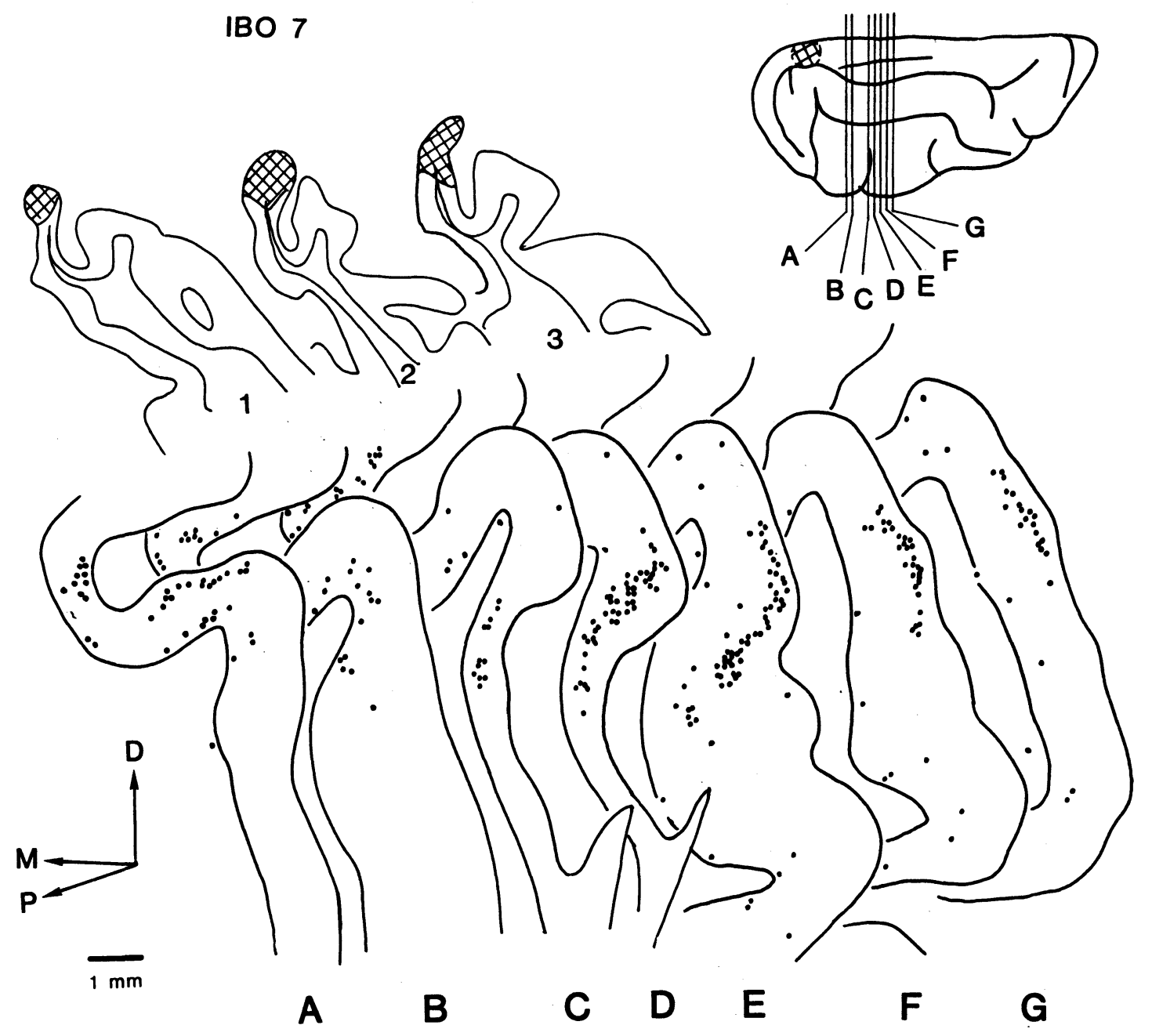

Fig. 9: Charts showing distribution of retrogradely labeled neurons in ipsilateral ectosylvian auditory region following injections in the microcortex (areas 17 and 18). The injection site is shown in small section drawings (1-3, from posterior to anterior) and on brain figurine which also shows levels of section. The injection is restricted to three-layered microcortex. Arrows indicate dorsal $(D)$, medial $(M)$ and posterior $(P)$ directions. 
In animals which passed these criteria (all of those in Table 1), labeled axons could be found which separated from those directed to the $\mathrm{CC}$, near the roof of the lateral ventricle, and continued with a dorsally ascending trajectory in the white matter of the lateral gyrus, towards areas 17 and 18. Other axons branched towards area 19. These trajectories are similar to those of axons which in normal development project transitorily from auditory to visual areas $/ 33 /$.

The axons entered selectively the injured part of the lateral and postlateral gyri. Invariably this happened not only in regions where a true microcortex had developed but also in the surrounding, transitional zone, where only layer VI was completely or partially destroyed. The density of the precipitate varied from animal to animal, apparently in relation with the accuracy by which the region with auditory-to-visual projecting neurons was involved. In the best cases the target cortex was filled in all its thickness, although the density is higher at the bottom of the cortex. Occasionally the terminals tended to accumulate in $200-300 \mu \mathrm{m}$-wide "columns" separated by spaces containing lighter precipitate (Fig. 10).

The presence of these axons seems due to the lesion: since they were never found in the intact cortex surrounding the microcortex and they were also not found in IBO 30 where the dose of ibo was insufficient to cause a lesion. Axons originating in the auditory cortex were also found in the areas 17 and 18 of one kitten (IBO 49) in which the late (on pd 7) ibo injection had resulted in more severe destruction than in the other, earlier ibo injected kittens. As described elsewhere /29/ (see Fig. $6 \mathrm{D}$ ), the cortex was reduced to a wider than normal layer I containing sparse neurons and a deeper, one or few cell thick neuronal layer.

The presence of terminating axons in the microcortex contrasts with the absence of retrogradely labeled neurons in the same cortex. The latter is not unexpected since no auditory-tovisual projection appears to exist at the age of ibo injection or later $/ 33 /$.

\section{Development of the auditory-to-visual projection following injections of ibotenic acid}

The behavior of the auditory-to-visual projection near its target was studied in 5 kittens injected with ibo on pd 2-3 and subsequently with WGA-HRP in AI-AII, at different postnatal ages (Table 1). The results were compared with those of similar injections in normal animals of approximately the same age, analyzed previously 133/. This was done in order to control that the projection seen in adults did result from the stabilization of the normally transient juvenile auditory-to-visual projection rather than from a lesion-induced new outgrowth of a projection. We also hoped to capture events useful for

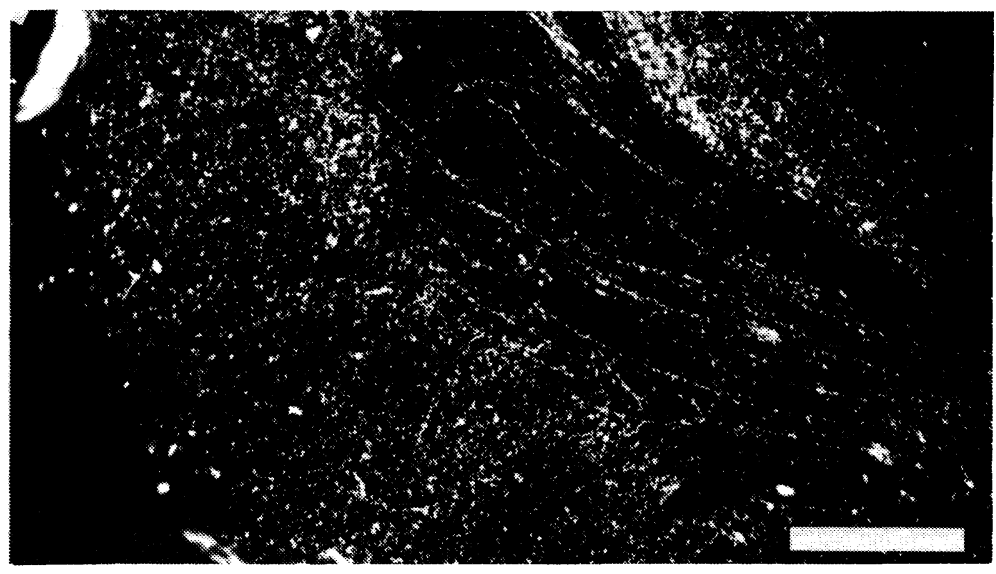

Fig. 10: Polarized light photomicrographs of axonal projections to microcortical areas 17 (on the left; medial bank of lateral gyrus) and 18 (on the right) in IBO 13. WGA-HRP was injected in the middle ectosylvian region and involved areas Al and All. Bar is $200 \mu \mathrm{m}$. 
understanding the mechanisms of the stabilization.

In the youngest of these kittens (IBO 47, injected with tracer at pd 10) several labeled axons reached the microcortex of the lateral and postlateral gyri, which some of them entered. Occasionally, single axons could be followed as far as layer I. A similar projection reached the convexity of the suprasylvian gyrus. Growth cones could be seen in the white matter along the trajectory of these axons. Fewer axons could be followed also to the contralateral, normal visual areas; they only exceptionally entered the gray matter. Both the ipsilateral and contralateral axonal projections were identical to those described in normal kittens of comparable age /33/.

The first animal in which a difference between the auditory projection to normal and microcortical areas 17 and 18 could be found was IBO 98, killed on pd 14. In this animal, several axons were found in the ibo-injected parts of the postlateral gyrus (Fig. 11) but not elsewhere in the intact cortex. These axons seemed more numerous than anywhere in the lateral and postlateral gyri of a normal animal (Fig. 12) of comparable age. In the kitten killed on day 18 (IBO 45) some labeled axons were similarly found in the white matter of the lesioned part of the lateral gyrus but unfortunately in this animal the ibo injection had lesioned the white matter and the WGA-HRP injection site was very small.

The animals killed on pd 27 (IBO 46) and 41 (IBO 43a) were similar to each other and were very different from normals of comparable age. In both cases, terminating axons were seen in the microcortical part of the postlateral gyrus. They extended over the whole thickness of the gray matter of both areas 17 and 18 although they had a tendency to being densest near the convexity of the postlateral gyrus. Unlike in younger lesioned or normal kittens where the axons in gray matter were continuously labeled and appeared unbranched, the labeling was now dusty suggesting that the axons may have developed terminal arbors. Continuously labeled axon segments were, however, also seen, especially in the white matter.

Axons had completely disappeared from the other parts of cortex where they were regularly found in younger kittens, in particular in the lateral-postlateral and suprasylvian gyri contralateral to the lesion. In order to be sure that ipsilateral auditory axons to these areas, not only the callosal ones, had been eliminated, in IBO 46 , the auditory areas on both sides had been injected (Table 1).

\section{DISCUSSION}

\section{General structure of ibo-induced microcortex}

On the basis of several criteria, including cytoarchitectonics, cell composition and developmental history, we previously suggested that the microcortex induced by neonatal injections of ibo consists of neurons which would normally give rise to the supragranular layers II and III /29/. Consistent with this interpretation we now found that the microcortex lacks the main corticosubcortical projections, which originate from the infragranular layers $/ 17,18 /$, as well as the callosal projections which originate from layer VI and, more massively, from layer IV and the deep part of III /24/. The absence of callosal projections from supragranular layers could not have been anticipated from the cytoarchitecture of the microcortex. It indicates that although layer III is present it may be incomplete. This is compatible with the hypothesis /29/ that ibotenic acid deletes most of the neurons that have completed migration at the time of injection.

Projections to within areas 17 or 18 , or from 17 to 18 are preserved as one would have expected, since these projections originate mostly from layers II and III /17,35,55,68/.

In addition to supporting the previous interpretations on the cellular composition and origin of the microcortex induced by neonatal injections of ibo, this finding stresses the robustness and resistance against epigenetic perturbations of one of the most specific features of cortical organization, i.e., the radially specific origin of corticofugal projections. The supragranular layers, of which the microcortex consists, do not establish projections to the structures which normally receive afferents from the missing layers. Neither the change in their relative radial position in the cortex (i.e., the fact of being closer to the white matter) nor the absence of competitors seems sufficient to induce layer II and III neurons to form connections in subcortical targets. What causes the radially specific origin of corticofugal projections is unclear, although birth- 


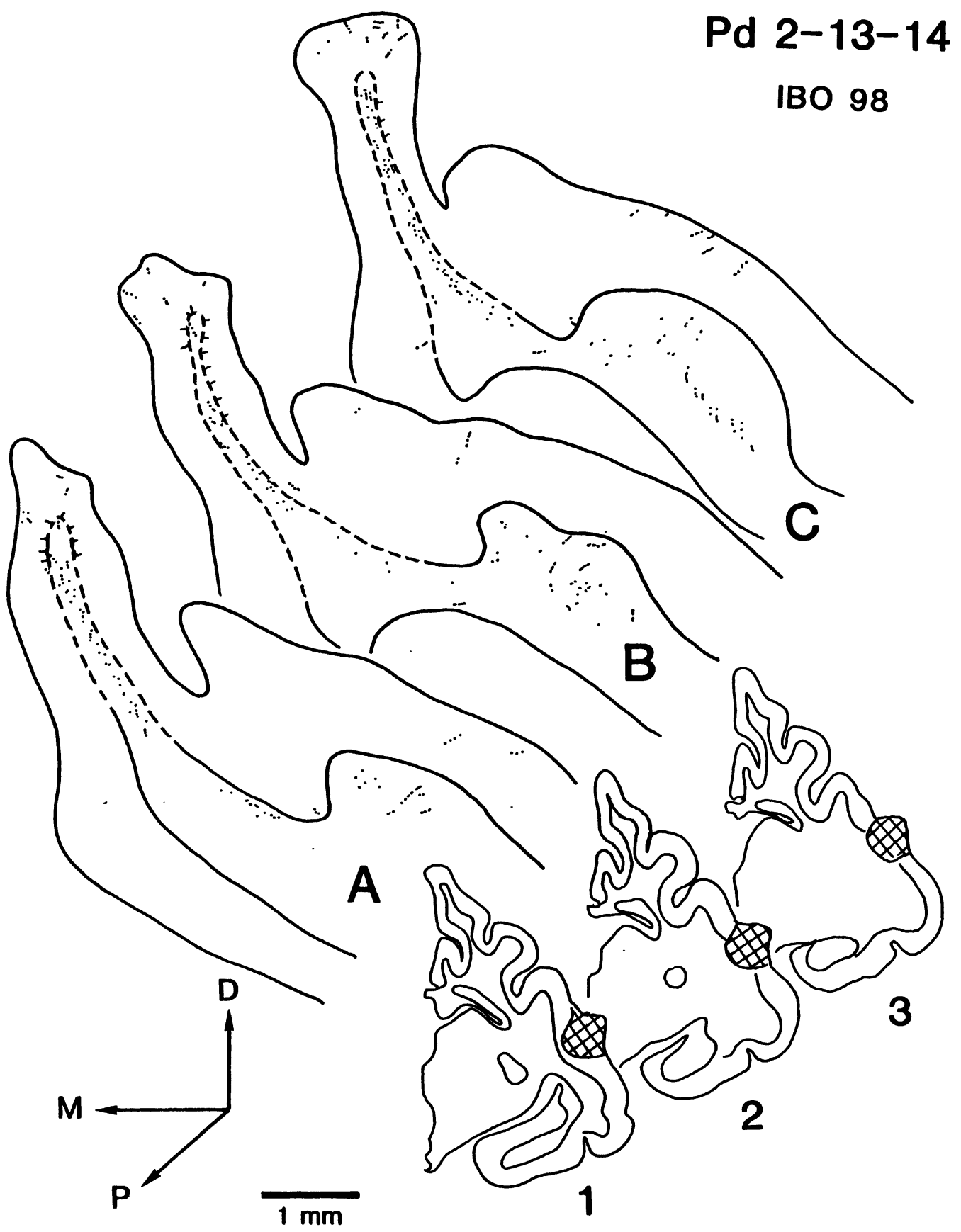

Fig. 11: Sketches of axonal projections (small dots) from auditory, to microcortical visual areas (17 on the left, 18 on the right of postlateral gyrus) of the same hemisphere. Age at ibo injection, WGA-HRP injection, and sacrifice, and animal code are indicated. Smaller drawings (1-3 from caudal to rostral) show site of injection (cross hatched). In each section a continuous line denotes the bottom of normal layer VI. An interrupted line denotes the bottom of the thinned layer VI, usually accompanied by degeneration of layer V. $T(s)$ denote the bottom of three layered microcortex. Arrows indicate dorsal $(D)$, medial $(M)$ and posterior (P) directions. 


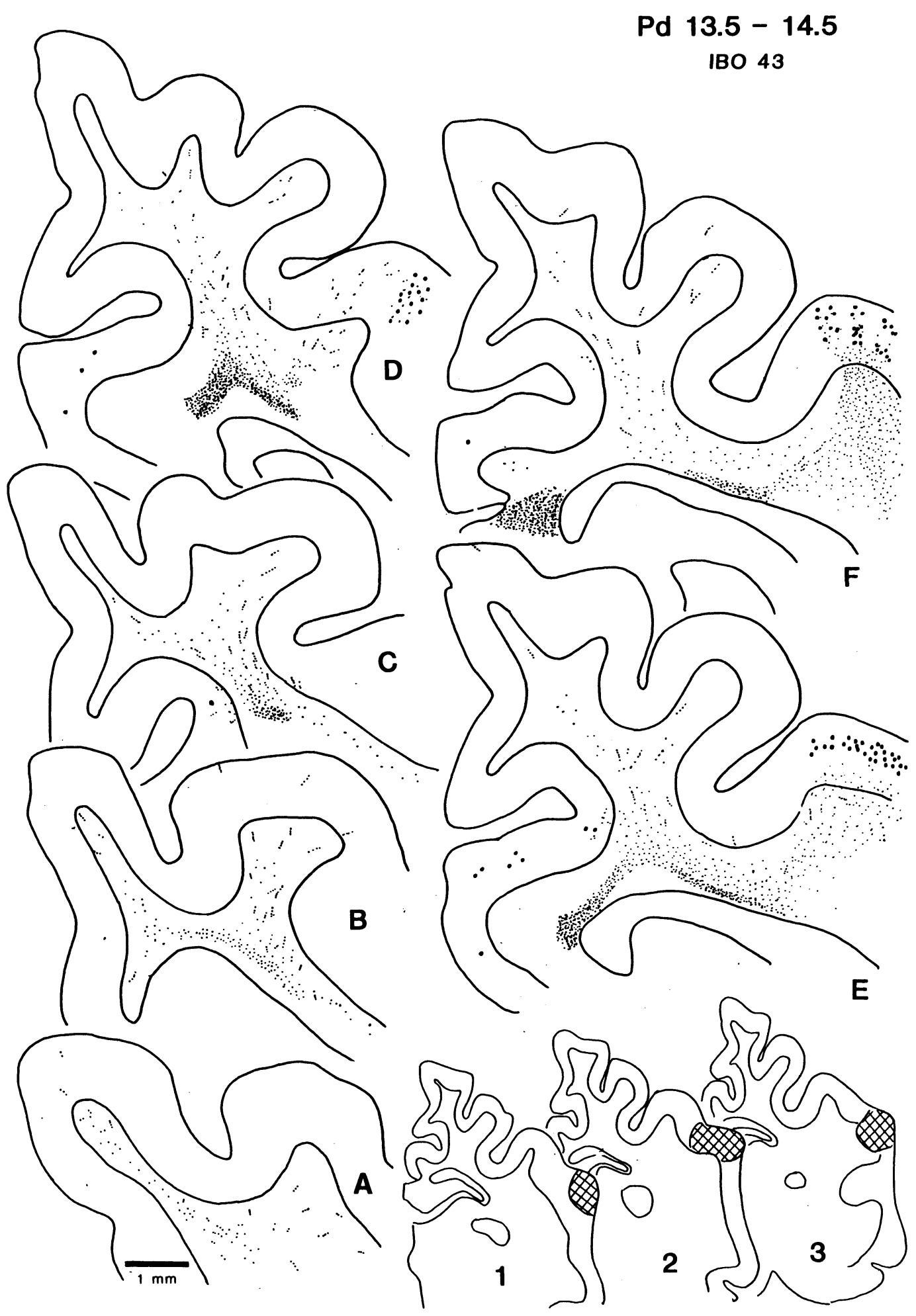

Fig. 12: Sketches of axonal projections from auditory to visual areas in a normal kitten. Age at WGA-HRP injection and sacrifice, and animal code are indicated. Sections (from A to E) are ordered from caudal to rostral. Other conventions as in Fig. 11. 
date, position in a cell lineage or clonal origin may be involved (for discussion see refs. /28, 32/).

Whatever the developmental mechanism, the microcortex lacks a certain number of projections and this offers new possibilities for studying the functional or morphogenetic role of these projections and of the neurons from which they originate.

It was puzzling to find that the microcortex receives thalamic afferents from the dLGN in the absence of layer IV, the main recipient of this projection in normal animals $/ 16,45 /$. The finding has two possible explanations: i) afferents from the dLGN may invade layers II and III, or they may remain restricted to the bottom of layer III and to layer I where they normally terminate /45/. Recent findings $/ 1$ / seem to favor the second alternative and raise the question of the function of this abnormal thalamocortical projection. Surprisingly, the microcortex still shows a number of normal response properties, including orientation and direction selectivity /1,34/.

Interestingly, callosal afferents reach the microcortex but do not originate from it. Callosal afferents to the microcortex originate from their normal contralateral sites, in particular, in areas 17 and 18 where they are restricted to a strip near the common border between these two areas. Their termination is also restricted, apparently to the region where they would terminate in normal adults.

Thus, it appears that the development of callosal connections between areas 17 and 18 in the two hemispheres, in particular the focussing of callosal connections to the $17 / 18$ border, does not require reciprocal interhemispheric interactions between these areas. Furthermore, either, as previously suggested $/ 26 /$, callosal neurons are not the main target of callosal axons or the latter can be induced to terminate on targets other than their normal ones.

Finally, we have seen that the microcortex receives a number of corticocortical afferents which would normally go to areas 17 and 18 . To what extent each of these projections is normal in all respects, can be decided only by a more detailed study than that afforded here. Some of the connections seem, however, to be abnormal. In particular, a massive labeling of neurons extending as far as the splenial sulcus was not previously seen after injections localized to the crown of the lateral and postlateral gyri in nor- mal adults where neuronal labeling much more circumscribed to near the site of tracer injection was instead found $/ 35 /$. It is probable that the tangentially widespread connections found in the microcortex are stabilized juvenile exuberant projections which were demonstrated between areas 17 and 18 or intrinsic to area 17 $/ 10,39,48,55 /$.

The stabilization of exuberant projections seems to be a plausible explanation for the finding that microcortical areas 17 and 18 receive abnormal afferents from ipsi- and contralateral auditory cortex. Transient projections from auditory to visual areas are lost by axonal elimination during the 1st and 2nd postnatal month $/ 11,30,32 /$. The neurons from which the transient projections originate would normally establish permanent projections within the ipsilateral hemisphere, but only short ones, which, in the case of neurons in AI and AII, reach other auditory areas. That the auditory projection to the microcortex should be a stabilized juvenile projection rather than a projection which was destined to some other cortical site and was misrouted to the microcortex, or else a projection whose growth was induced by the application of ibotenic acid and subsequent lesion is supported by the following considerations. The auditory-tomicrocortex projection originates from the same layers as the transient projection. Second, the analysis of the projection at short intervals following the ibo injection did not give any indication of lesion-induced "de novo" growth or axonal misrouting. It rather indicated that axons which are normally in the target cortex or near it at the time of ibo injection escape elimination.

\section{Developmental exuberance and the emergence of neural networks}

It has been clear for some years that several nervous system connections undergo in development a phase of "exuberance" during which more neurons, axons and synapses are formed than are found in the adult (see for review, refs. $12,8,9,12,13,27 /$; inter alia). In certain structures, particularly in the visual system $15,23,44,56,62 /$ and in the cerebral cortex $/ 14,36,37 /$ projections were demonstrated which are very different from those found in the adult. In a subsequent phase of "reshaping", neurons 
die, axons are shed, synapses disappear and out of these regressive events the adult neural circuits emerge.

The interest in these developmental events is justified by the impression that they may help to clarify the mechanisms responsible for the formation of specific connections in the central nervous system, at least in those cases in which specificity appears to involve selection of preand postsynaptic sets of neuronal elements. Furthermore, the juvenile nervous system seems to have potentials for connections well in excess of those normally expressed and this may have practical consequences in the prevention or treatment of diseases of the immature brain.

The present experiments were meant to test the role of the target in the selection of the juvenile afferents and in particular the classical concept that growing axons depend on trophic support from the target, compete for it, and the losers are eliminated (see refs. $77,9,13,25,47$, $57 /$ inter alia). Our results, however, differ from those of deletion of peripheral and central targets on which the above concept is based. Instead of the expected increased elimination of juvenile afferents we obtained, with partial deletion of the target, the stabilization of afferents which are normally eliminated. The difference between the results of the classical experiments and ours is particularly striking in the case of the animal injected with ibo on pd 6-7, in which stabilization of the auditory-to-visual projection was obtained even though the target cortex was reduced to a few-cell-thick layers (Figs. 6, 7 in ref. 129/).

It could be that the partial target deletion increased, rather than decreased the production of putative trophic substances by the target /52/. Ibotenic acid injections initially provoke an increase of macrophages and a loss of astrocytes, followed within 1 - 2 weeks by loss of the first and increase of the second /29/. Astrocytes may release substances which directly or indirectly enhance axonal survival (for discussion see ref. 153/). This mechanism, however, is somewhat improbable given the fact that the transient axons from area 17 are not stabilized and the stabilization of axons from auditory areas outlasts the effect of injury.

Alternatively, the neonatal ibo injection may have resulted in the elimination of axons which normally successfully compete with juvenile ax- ons, leading to elimination of the latter. Since the microcortex, at least qualitatively, seems to receive all the afferents which go to the normal visual cortex, the elimination of afferents is unlikely. Elimination of input from the eyes by neonatal bilateral enucleation /33/ or interruption of the thalamic radiation $/ 51 /$ do not lead to stabilization of the auditory-to-visual projection. However, the competing axons may be of intrinsic origin.

Consistent with this interpretation we found that the early destruction of layer VI neurons appears to be a sufficient condition for the maintenance of an otherwise transient projection from auditory areas to visual areas. Axons originating in auditory areas were found to enter peripheral regions of the microcortex, where only layer VI was destroyed, or partially destroyed, by the early ibo injection. Thus in development layer VI neurons may eliminate certain afferents to areas 17 and 18 . There may be similarities between the roles these neurons play in adulthood and in development.

In the adult cortex, layer VI neurons send "feed back" projections to layer IV and to structures afferent to it, including the dLGN and other cortical areas $/ 17,18,42,46,50,68 /$. Their position makes them probable targets of dLGN afferents $/ 45 /$, as well as of other cortical afferents and of local intracortical projections. These neurons seem capable of enhancing certain aspects of the input to the cerebral cortex while suppressing others, resulting in modification of the structure of cortical receptive fields possibly related to attentional phenomena $/ 43,66 /$.

Through a similar, or different mechanism, these neurons may gate admission to the cortex or maintenance of juvenile axons in development. However, destruction of layer VI is not sufficient for the stabilization of projections from contralateral area 17. Furthermore, although areas 17 and 18 receive juvenile projections from large territories in the ipsi- and contralateral hemisphere, the stabilized projections originate specifically in a small portion of the auditory areas. Another factor, therefore, must be responsible for the differential stabilization of different transient projections.

The competition hypothesis (see ref. /22/, for review) can in principle provide sufficient explanation for a broad range of developmental phenomena. However, models of development of 
orderly connections have required in addition to competition the assumption that pre- and postsynaptic elements are heterogenous because they carry some chemical or electrical markers (see for example refs. /15/ and /69/). Differential molecular affinities between axons of different origin and different parts of area 17 may play a role in the selection of afferents to this area.

\section{ACKNOWLEDGEMENTS}

This work was supported by Swiss National Science Foundation Grant 3.359-0.86 to GMI, by a fellowship from the Spanish "Consejo Superior de Investigaciones Cientificas" to PB. Ibotenic acid was kindly provided by Dr. Eugster. We are grateful to S. Daldoss and Ch. Vaclavik for their help at various stages of this work.

\section{REFERENCES}

1. Assal F, Melzer P, Innocenti GM. Functional analysis of a visual cortical circuit resembling human microgyria. Europ J Neurosci Suppl 1989 Suppl. 2: 256.

2. Bennett MR. Trophic interactions at synapses and the survival of central neurones. In: Chagas $C$, Linden $R$ (eds.), Developmental Neurobiology of Mammals. Pontificia Academia Scientiarum, 1985; pp. 141-216.

3. Bentivoglio M, Kuypers HGJM, Catsman-Berrevoets CE, Loewe H, Dann O. Two new fluorescent retrograde neuronal tracers which are transported over long distances. Neurosci Lett 1980; 18: 25-30.

4. Berman N, Cynader M. Comparison of receptivefield organization of the superior colliculus in Siamese and normal cats. J Physiol (London) 1972; 224: 363-389.

5. Bunt SM, Lund RD. Development of a transient retinoretinal pathway in hooded and albino rats. Brain Res 1981; 211: 399-404.

6. Caminiti R, Zeger S, Johnson PB, Urbano A, Georgopoulos AP. Corticocortical efferent systems in the monkey: a quantitative spatial analysis of the tangential distribution of cells of origin. J Comp Neurol 1985; 241: 405-419.

7. Carpenter P, Sefton AJ, Dreher B, Lim W-L. Role of target tissue in regulating the development of retinal ganglion cells in the albino rat: effects of kainate lesions in the superior colliculus. J Comp Neurol 1986; 252: $240-259$

8. Changeux J-P, Danchin A. Selective stabilisation of developing synapses as a mechanism for the specification of neuronal networks. Nature 1976; 264: 705712.
9. Clarke PGH. Neuronal death in the development of the vertebrate nervous system. TINS 1985; 8: 345-349.

10. Clarke S, Innocenti GM. Organization of immature intrahemispheric connections. J Comp Neurol 1986; 251: 1-22.

11. Clarke S, Innocenti GM. Auditory neurons with transitory axons to visual areas form short permanent projections. Europ J Neurosci 1990; 2:227-242.

12. Cowan WM. Neuronal death as a regulative mechanism in the control of cell number in the nervous system. In: Rockstein M (ed.), Development and Aging in the Nervous System. New York: Academic Press, 1973; pp. 19-41.

13. Cowan WM. Fawcett JW, O'Leary DDM, Stanfield BB. Regressive events in neurogenesis. Science 1984; 225: 1258-1265.

14. Distel $\mathrm{H}$, Holländer $\mathrm{H}$. Autoradiographic tracing of developing subcortical projections of the occipital region in fetal rabbits. J Comp Neurol 1980; 192: 505518.

15. Fraser SE. Cell interactions involved in neuronal patterning. An experimental and theoretical approach. In Edelman GM, Gall WE, Cowan WM (eds.), Molecular Bases of Neural Development. New York: John Wiley \& Sons, 1985; 481-507.

16. Garey LJ, Powell TPS. An experimental study of the termination of the lateral geniculo-cortical pathway in the cat monkey. Proc R Soc Lond B 1971; 179: 4163.

17. Gilbert CD, Kelly JP. The projections of cells in different layers of the cat's visual cortex. J Comp Neurol 1975; 163: 81-106.

18. Gilbert $C D$, Wiesel TN. Laminar specialization and intracortical connections in cat primary visual cortex. In: Schmitt FO, Worden FG, Adelman G, Dennis SG (eds.), The Organization of the cerebral cortex. Cambridge, London: The MIT Press, 1981; pp. 163-191.

19. Gilbert CD, Wiesel TN. Clustered intrinsic connections in cat visual cortex. J Neurosci 1983; 3: 1116-1133.

20. Glaser EM, Van der Loos H. A semi-automatic computer-microscope for the analysis of neuronal morphology. IEEE Trans. bio-med. Eng. 1965; BME12: 22-31.

21. Guillery RW. A study of Golgi preparations from the dorsal lateral geniculate nucleus of the adult cat. J Comp Neurol 1966; 128: 21-50.

22. Guillery RW. Competition in the development of the visual pathways. In: Parnavelas JG, Stern CD, Stirling RV (eds.), The Making of the Nervous System. Oxford, New York, Tokyo: Oxford University Press, 1988; pp. 356-379.

23. Hubel DH, Wiesel TN, LeVay S. Plasticity of ocular dominance columns in monkey striate cortex. Phil Trans R Soc Lond B 1977; 278: 377-409.

24. Innocenti GM. The primary visual pathway through the corpus callosum: morphological and functional aspects in the cat. Arch Ital Biol 1980; 118: 124-188. 
25. Innocenti GM. Transitory structures as substrate for developmental plasticity of the brain. In: Van Hof MW (ed.), Functional Recovery from Brain Damage. Amsterdam: Elsevier, 1981; pp. 305-333.

26. Innocenti GM. General organization of callosal connections in the cerebral cortex. In: Jones EG, Peters A (eds.), Cerebral Cortex, Vol. 5. London, New York: Plenum Publishing Corporation, 1986; 291-353.

27. Innocenti GM. Loss of axonal projections in the development of the mammalian brain. In: Parnavelas JG, Stern CD, Stirling RV (eds.), The Making of the Nervous System. Oxford, New York, Tokyo: Oxford University Press, 1988; pp. 319-339.

28. Innocenti GM. The development of projections from cerebral cortex.. Progr Sens Physiol (1990) in press.

29. Innocenti GM, Berbel P. Analysis of an experimental cortical network: i) architectonics of visual areas 17 and 18 after neonatal injections of ibotenic acid; similarities with human microgyria. J Neur Transpl 1991; 2: $1-28$

30. Innocenti GM, Berbel $P$, Aschoff A, Melzer P. Connections and functional properties of an experimental cortical network. Europ J Neurosci 1988: 334.

31. Innocenti GM, Clarke S. Bilateral transitory projection to visual areas from auditory cortex in kittens. Dev Brain Res 1984a; 14: 143-148.

32. Innocenti GM, Clarke S. The organization of immature callosal connections. J Comp Neurol 1984b; 230: 287-309.

33. Innocenti GM, Berbel P, Clarke S. Development of projections from auditory to visual areas in the cat. J Comp Neurol 1988; 272: 242-259.

34. Innocenti GM, Berbel P, Melzer P. Stabilization of transitory corticocortical projections following lesions provoked by neonatal ibotenic acid injections. Neuroscience 1987; 22: S227.

35. Innocenti GM, Clarke S, Kraftsik R. Interchange of callosal and association projections in the developing visual cortex. J Neurosci 1986; 6: 1384-1409.

36. Innocenti GM, Fiore L, Caminiti R. Exuberant projection into the corpus callosum from the visual cortex of newborn cats. Neurosci Lett 1977; 4: 237-242.

37. Ivy GO, Killackey HP. The ontogeny of the distribution of callosal projection neurons in the rat parietal cortex. J Comp Neurol 1981; 195: 367-389.

38. Kalia $M$, Whitteridge $D$. The visual areas in the splenial sulcus of the cat. J Physiol (London) 1973; 232: 272-283.

39. Katz LC, Wiesel TN. Postnatal development of intrinsic axonal arbors of pyramidal neurons in cat striate cortex. Neurosci Abs 1987; 13: 1025.

40. Katz LC, Burkhalter A, Dreyer WJ. Fluorescent latex microspheres as a retrograde neuronal marker for in vivo and in vitro studies of visual cortex. Nature 1984 310: 498-500.

41. Keizer K, Kuypers HGJM, Huisman AM, Dann O. Diamidino yellow dihydrochloride (DY-2HCl); a new fluorescent retrograde neuronal tracer, which mi- grates only very slowly out of the cell. Exp Brain Res 1983; 51: 179-191.

42. Keller G, Innocenti GM. Callosal connections of suprasylvian visual areas in the cat. Neuroscience 1981; 6: 703-712.

43. Koch $C$. The action of the corticofugal pathway on sensory thalamic nuclei: a hypothesis. Neuroscience 1987; 23: 399-406.

44. Land PW, Lund RD. Development of the rat's uncrossed retinotectal pathway and its relation to plasticity studies. Science 1979; 205: 698-700.

45. LeVay S, Gilbert CD. Laminar patterns of geniculocortical projection in the cat. Brain Res 1976; 113: 119.

46. LeVay S, Sherk $H$. The visual claustrum of the cat. I. Structure and connections. J Neurosci 1981; 1: 956980.

47. Levi-Montalcini R, Calissano P. Nerve growth factor as a paradigm for other polypeptide growth factors. TINS 1986; 9: 473-477.

48. Luhmann HJ, Martinez Millan L, Singer W. Development of horizontal intrinsic connections in cat striate cortex. Exp Brain Res 1986; 63: 443-448.

49. Matsubara J, Cynader M, Swindale NV, Stryker P. Intrinsic projections within visual cortex: evidence for orientation-specific local connections. Proc Natl Acad Sci USA 1985; 82: 935-959.

50. McGuire BA, Hornung J-P, Gilbert CD, Wiesel TN. Patterns of synaptic input to layer 4 of cat striate cortex. J Neurosci 1984; 4: 3021-3033.

51. Melzer P, Rothblatt LA, Innocenti GM. Lesions involving the optic radiation in kittens modify the postnatal development of corticocortical connections. Neuroscience 1987; 22: S223.

52. Nieto-Sampedro M, Lewis ER, Cotman CW, Manthorpe M, Skaper SD, Barbin G, Longo FM, Varon S. Brain injury causes a time-dependent increase in neuronotrophic activity at the lesion site. Science 1982; 217: 860-861.

53. Nieto-Sampedro M, Manthorpe M, Barbin G, Varon $S$, Cotman CW. Injury-induced neuronotrophic activity in adult rat brain: correlation with survival of delayed implants in the wound cavity. J Neurosci 1983 ; 3: 2219-2229.

54. Palmer LA, Rosenquist AC, Tusa RJ. The retinotopic organization of lateral suprasylvian visual areas in the cat. J Comp Neurol 1978; 177: 237-256.

55. Price DJ, Blakemore C. The postnatal development of the association projection from visual cortical area 17 to area 18 in the cat. J Neurosci 1985; 5: 24432452.

56. Rakic P. Prenatal genesis of connections subserving ocular dominance in the rhesus monkey. Nature 1976; 261: 467-471

57. Rakic P. Development of visual centers in the primate brain depends on binocular competition before birth. Science 1981; 24: 928-931.

58. Reale RA, Imig TJ. Tonotopic organization in audi- 
tory cortex of the cat. J Comp Neurol 1981; 192: 265291.

59. Reinoso-Suarez F. Topographischer Hirnatlas der Katze für experimental-physiologische Untersuchungen. Darmstadt: E. Merck AG, 1961.

60. Rosenquist $\mathrm{AC}$. Connections of visual cortical areas in the cat. In: Peters A, Jones EG (eds.), Cerebral Cortex, Vol. 3. London, New York: Plenum Publishing Corporation, 1985; pp. 81-117.

61. Sanderson KJ. The projection of the visual field to the lateral geniculate and medial interlaminar nuclei in the cat. J Comp Neurol 1971; 143: 101-118.

62. Schneider GE, Jhaveri S, Davis WF. On the development of neuronal arbors. In: Chagas $C$, Linden $R$ (eds.), Developmental Neurobiology of Mammals. Pontificia Academia Scientiarum, 1985; pp. 31-65.

63. Segraves MA, Innocenti GM. Comparison of the distributions of ipsilaterally and contralaterally projecting corticocortical neurons in cat visual cortex using two fluorescent tracers. J Neurosci 1985; 5: 2107. 2118.

64. Segraves MA, Rosenquist AC. The afferent and efferent callosal connections of retinotopically defined areas in cat cortex. J Neurosci 1982a; 2: 1090-1107.

65. Segraves MA, Rosenquist AC. The distribution of the cells of origin of callosal projections in cat visual cortex. J Neurosci 1982b; 2: 1079-1089.

66. Singer W. Control of thalamic transmission by corticofugal and ascending reticular pathways in the visual system. Physiol Rev 1977; 57: 386-420.

67. Symonds LL, Rosenquist AC. Corticocortical connections among visual areas in the cat. J Comp Neurol 1984; 229: 1-38.

68. Symonds LL, Rosenquist AC. Laminar origins of visual corticocortical connections in the cat. J Comp Neurol 1984; 229: 39-47.

69. Von der Malsburg C, Willshaw D. Co-operativity and brain organization. TINS 1980; 4: 80-83. 

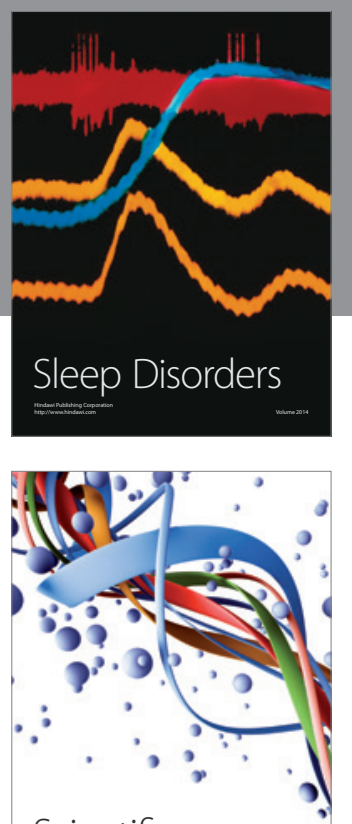

Scientifica
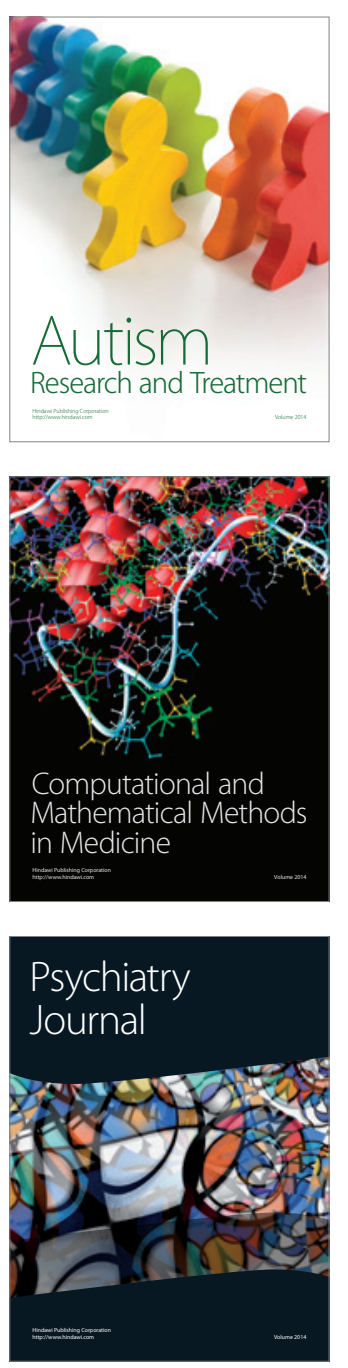
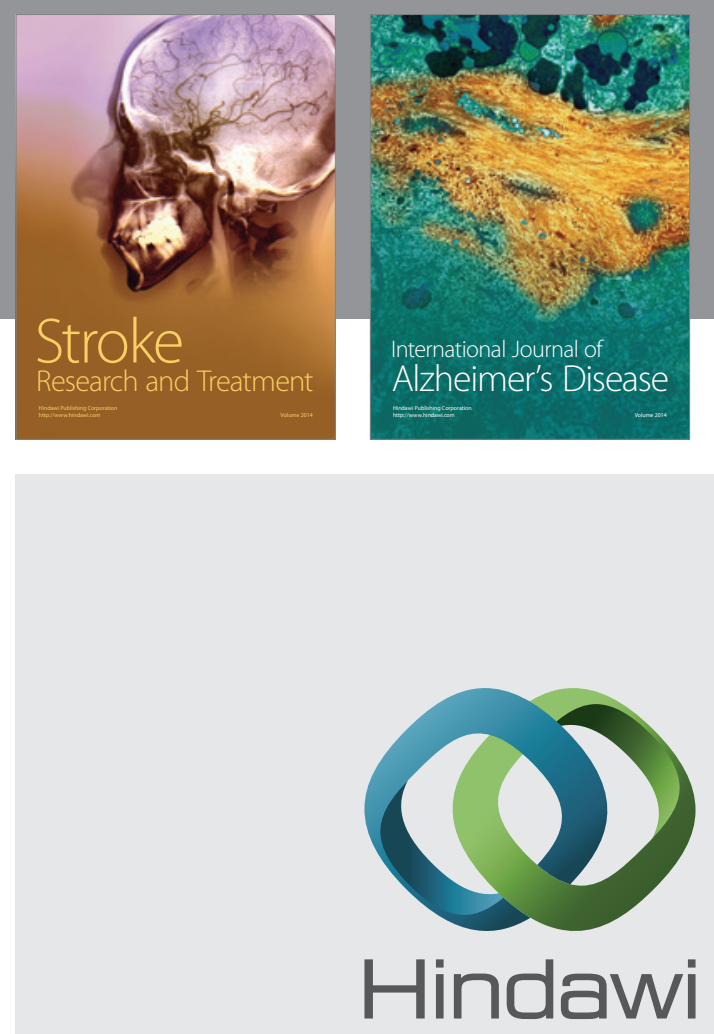

Submit your manuscripts at

http://www.hindawi.com
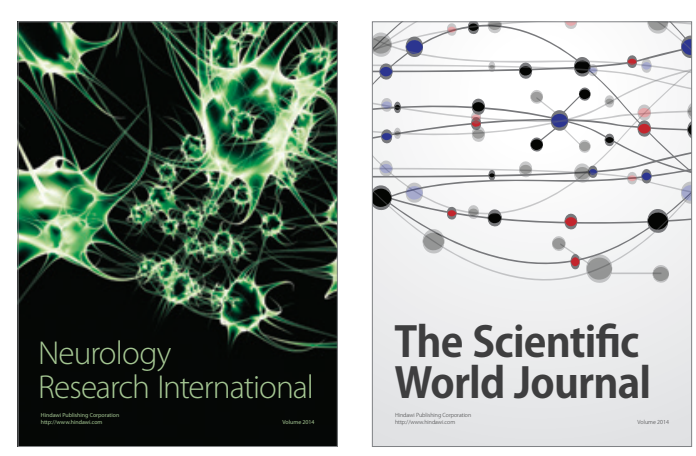

The Scientific World Journal

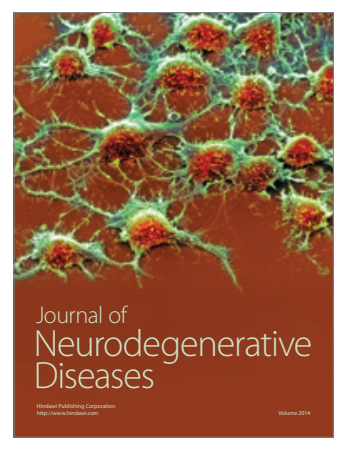

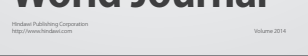

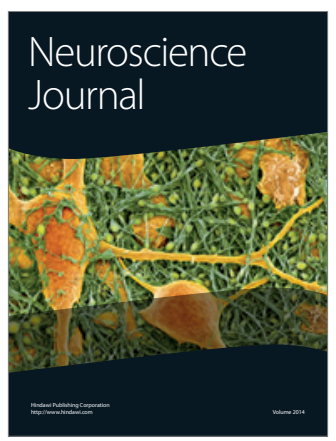

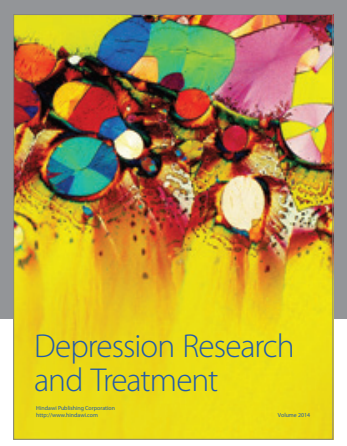
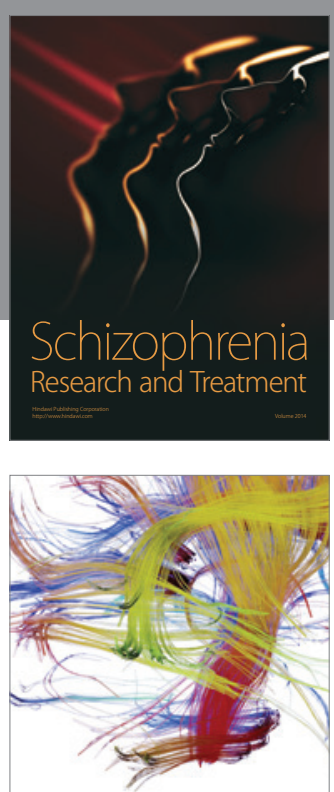

Brain Science

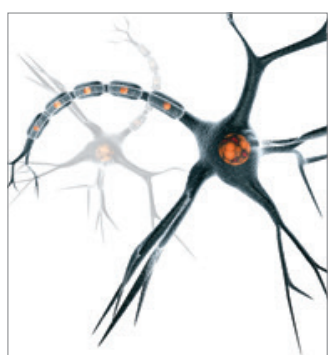

Neural Plasticity
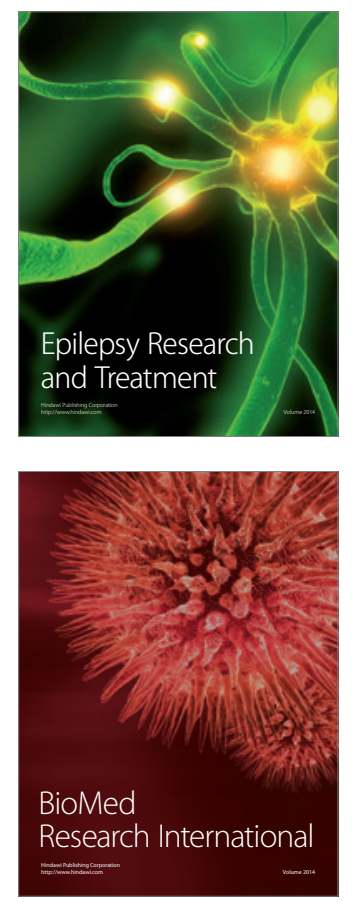

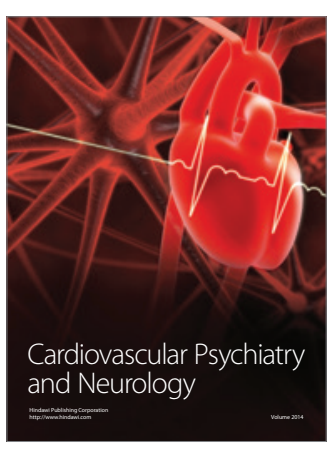

Parkinson's

Disease
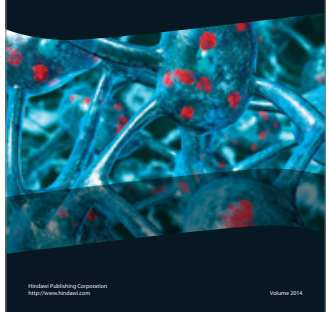